\title{
Exposições em museus de ciências: reflexões e critérios para análise ${ }^{1}$
}

\section{Maria-Júlia Estefânia Chelini' ${ }^{2}$ \\ Sônia Godoy Bueno de Carvalho Lopes ${ }^{3}$}

Un message chiffré, une lettre ouverte. Un billet doux, une circulaire. Une flûte à bec, une règle à calcul...

Un défi lancé à l'objet qui se tait, au chercheur qui ne croit qu'en son [bouquin, au public qui ricane ou baille,

passe et s'esquive..

L'ennemi qu'on rencontre, quand on cherchait l'ami...

Un langage visuel, de preference à tout autre...

Une chose que l'on pense et apprivoise, dédie et prépare en

[conséquence, éprouve et réalise..

Qui tue ou perpétue..

C'est tout cela au musée, la présentation.

Georges Henri Rivière (1989)

RESUMO: Hoje, no que diz respeito à sua interface direta com o público, os museus são considerados, em teoria, instituições com objetivos variados, como educação, lazer, informação e inclusão social. Neste contexto, as exposições aparecem como elemento fundamental da relação entre museus e sociedade, e a expografia torna-se, portanto, ferramenta de comunicação essencial para a efetividade do processo de divulgação. Mas, como se dá a comunicação nestes espaços? Trata-se o presente, de uma reflexão acerca das estratégias de comunicação nas exposições em museus de ciências e sua eficácia. Foram selecionadas três temáticas, a primeira delas é a dos tipos de exposição, e entre as numerosas possibilidades de categorização, optou-se por aquelas descritas por Dean (2003) e Davallon (1986 e 1989). Outra questão discutida é a do uso do objeto, tido, dentre as diferentes mídias a que se pode recorrer em uma exposição, como o diferencial do museu. Por fim, discute-se a questão da interatividade, por vezes reduzida à manipulação, a partir dos níveis propostos por Wagensberg (2000). Apontam-se exemplificações dessas temáticas na
1. Agradecemos ao programa de Pós-graduação em Zoologia, Instituto de Biociências-USP, pelo apoio ao projeto de doutorado que originou este trabalho; ao Museu de Zoologia pela autorização para publicação das imagens da exposição; ao fotógrafo José Rosael pela produção das imagens; ao museólogo Maurício Cândido da Silva, Supervisor do Serviço de Museografia do Museu de Zoologia, e a professora Heloisa Barbuy pela prestimosa ajuda.

2. Doutora em Ciências (Zoologia) pelo Instituto de Biociências da USP; Analista de Comunicação no Museu Paulista da USP. E-mail: $<$ jchelini@usp.br>.

3. Docente do Departamento de Zoologia, Instituto de Biociências da USP. E-mail: sonialop@ib.usp.br. 
4. Este termo vem sendo questionado em outras tipologias de museu por dar o sentido de uma comunicação unilateral. No entanto, em museus de ciências, tal denominação ainda é amplamente empregada, com o sentido de ação visando a tornar acessível ao público em geral o que é de domínio de cientistas.

5. Ver A. M. Galopim de Car valho (1993); John H. Falk \& Lynn D. Dierking (2000); e John H. Falk (2001).

6. Cf. P. Fayard (1999, p. 10).

7. Cf. Clara Correia d'Alambert \& Marina Garrido Monteiro (1990, p. 11). exposição de longa duração Pesquisa em Zoologia: a biodiversidade sob o othar do zoólogo, inaugurada pelo Museu de Zoologia da Universidade de São Paulo em setembro de 2002. PalaVRAS-CHAVE: Comunicação. Exposição. Museu de ciências. Museu de Zoologia da Universidade de São Paulo.

ABSTRACT: In respect to their direct interface with the public, museums nowadays are considered, in theory, institutions with a wide reach such as education, leisure, information and social inclusion. In this context, exhibitions emerge as a fundamental component in the relation between museums and society, and expography becomes an essential communicating tool for the effectiveness of the public communication process. But, how does this communication process occur in these places? The present work brings up a discussion on communication strategies in science museums and their effectiveness, focusing on three main themes. The first one refers to the different types of exhibitions and, although there are innumerous possibilities for classification, the ones described by Dean (2003) and Davallon (1986 and 1989) were followed here. Another question is the use of objects, considered, among the different media to which we can resource to in an exhibition, capable of making the museum stand out. Finally, we discuss the interactivity, sometimes reduced to manipulation, according to the levels described by Wagensberg (2000). Examples of these questions are indicated in the long-term exhibition Pesquisa em Zoologia: A Diversidade sob o Olhar do Zoólogo (Research in Zoology: Biodiversity through the eyes of a zoologist) that was opened at the Zoology Museum of the University of São Paulo in September 2002.

KEYWORDS: Communication. Exhibition. Science museum. Zoology Museum of the University of São Paulo.

Introdução

A divulgação ${ }^{4}$ científica é uma prática social que vem sendo cada vez mais ampliada e desenvolvida e, nesse aspecto, os museus ganham destaque como locais de comunicação e de educação não-formal. Talvez em função do consenso em relação à importância e necessidade de experiências fora da escola, que realmente auxiliem na compreensão do conhecimento científico ${ }^{5}$, o museu, a divulgação científica e a educação não-formal, pouco a pouco, têm se tornado, nos últimos anos e em especial no Brasil, objeto de maior número de iniciativas de investigação.

Fayard ${ }^{6}$ aponta que a generalização nas práticas de comunicação rompeu o isolamento da ciência e da vida científica e atenuou o desconhecimento público a respeito destas questões. Assim, novos espaços de intercâmbio contribuíram para a popularização da investigação e da tecnologia e instaurouse "o início de um diálogo entre ciência e sociedade".

Hoje, os museus, no que diz respeito a sua interface direta com o público, são considerados, em teoria, instituições com objetivos variados como educação, lazer, informação e inclusão social. Neste contexto, as exposições aparecem como elemento fundamental da relação entre museus e sociedade. Alambert e Monteiro ${ }^{7}$ apontam que a exposição transcende o agradável agrupamento de objetos em um determinado espaço físico. Para as autoras, ela 
é um meio de comunicação que permite ao público aprender e vivenciar experiências não somente intelectuais, mas também emocionais. Cury ${ }^{8}$ atribui às exposições dos museus a maior responsabilidade na mediação da relação entre homem e cultura material, relação que se fundamentaria como sendo de comunicação?

Na prática, é evidente a atual e gradual mudança que a natureza e o papel assumidos pelos museus frente à sociedade vêm sofrendo. Tais fatos levam a questionar os pressupostos teóricos e práticos que fundamentaram, e fundamentam, as ações museológicas nesses locais, em especial a expografia ${ }^{10}$.

\section{museu como divulgador}

Ao longo de toda a obra que reúne os textos de seu curso de museologia"1, Georges Henri Rivière estabelece que o museu é um meio de comunicação e que, independente do tipo de exposição, a museografia deve proporcionar um aporte de prazer e conhecimento. Esses dois elementos estariam ligados à essência de sua visão de museu e, como tais, não poderiam estar dissociados. $\bigcirc$ texto de Alexander ${ }^{12}$ reforça esta opinião ao definir, como objetivo das exposições, a comunicação com o público, utilizando objetos originais para inspirar ou informar e, até, proporcionar lazer.

Um século antes, o trabalho The Principles of Museum Administration, de George Brown Goode sobre a atuação, função e administração de museus, já definia como principais finalidades dessas instituições a contribuição para o avanço dos conhecimentos e para instrução e educação do público ${ }^{13}$. Esta dupla função - de colaborar com a educação e com a investigação científica - já havia sido citada, alguns anos antes, por William H. Flower em discurso de posse para presidência da British Association for the Advancement of Science, em setembro de 1889, como o novo papel conferido aos museus pela sua transformação em espaços públicos vinculados ao Estado ${ }^{14}$. Goode, na época diretor do Museu Nacional dos Estados Unidos, ressaltava, ainda, que o museu, local onde o público presencia o avanço do saber, deve, para cumprir suas finalidades, estimular o visitante por meio de "atrativas séries de exibição" 15 . Flower também havia se preocupado com as exposições enquanto parte da estratégia do museu para atingir, a contento, seu duplo objetivo. Para as coleções de investigação, Flower recomendava que não só estas fossem excessivamente numerosas, mas também que fossem instaladas de forma a permitir facilmente seu exame e comparações entre peças ou espécimes. Já para as exposições ao público, Flower recomendava que não se sobrecarregassem as vitrines e que a escolha dos objetos a serem expostos fosse cuidadosa ${ }^{16}$.

Em A conquista do caráter público do museu ${ }^{17}$, Valente explica que, a partir da segunda metade do século XIX le até certo ponto em função do interesse despertado pelas exposições internacionais), surgem museus cuja proposta é a
8. Cf. Marília Xavier Cury (2005, p. 368).

9. Idem, p. 367.

10. Embora seja possível encontrar na literatura os termos museografia e expografia empregados como sinônimos, entende-se que a museografia pode ser associada a um leque mais amplo de atividades desenvolvidas nos museus. Portanto, optou-se neste trabalho pelo emprego do termo expografia enquanto ação de materialização das exposições No entanto, quando a referência original fizer uso da denominação museografia o termo será mantido.

11. Ver Georges Henri Rivière (1989).

12. Cf. Edward P. Alexander (1979, p. 175).

13. George Brown Goode (1895), apud Ana Maria de Alencar Alves (2001, p. 83).

14. Cf. Maria Margaret Lopes \& Sandra Elena Murriello (2005, p. 21).

15. George Brown Goode (1895), apud Ana Maria de Alencar Alves (2001, p. 84).

16. Cf. Maria Margaret Lopes \& Sandra Elena Murriello (2005, p. 26).

17. Cf. Maria Esther Valente (2003, p. 35). 
18. Idem, p. 38.

19. Cf. Maria Esther Valente, Sibele Cazelli \& Fátima Alves (2005, p. 189)

20. Cf. A. M. Galopim de Carvalho (1993, p. 64).

21. Idem, p. 65

22. Idem, p. 61.

23. Cf. Jean Davallon (1989, p. 47).

24. Cf. Maria Esther Valente, Sibele Cazelli \& Fátima Alves $(2005$, p. 196)

25. Idem, p. 198 divulgação ao grande público de suas coleções e a vulgarização do saber. A autora acrescenta, ainda, que o esforço pela democratização, com a participação de um público cada vez mais numeroso, passa a ser uma das características dos museus de ciência e tecnologia que proliferaram durante o século XX ${ }^{18}$.

A década de 1980 é marcada, no Brasil, pelo surgimento dos primeiros museus de ciência e tecnologia com caráter dinâmico, buscando projetar-se como instituições de comunicação, educação e difusão cultural, voltadas para um público amplo e diversificado. Isto seria decorrente de um processo iniciado na década de 1960 e no qual os museus de ciência e tecnologia tiveram atuação preponderante ao assumir, para além dos propósitos tradicionais dos museus, a difusão de princípios científicos e tecnológicos, a fim de induzir os jovens às carreiras pertinentes a essas áreas ${ }^{19}$.

Carvalho ${ }^{20}$, por sua vez, expõe que, em uma época de crescentes agressões ecológicas, é papel do museu de ciências divulgar conhecimento científico, dirigindo-o especialmente àqueles (muitos) para os quais o saber é escasso ou mesmo inexistente. Completa, ainda, dizendo que é "obrigação" dos museus de ciências, através de seus pesquisadores e em especial dos professores universitários a eles vinculados, "divulgar o saber que vão adquirindo"21.

Assim, qualquer que seja o objetivo ideológico da instituição, torna-se claro que é função do museu de ciências a divulgação científica e que, nesse processo, é reservado importante papel às exposições. Ainda para Carvalho22, divulgar é "espalhar ou tornar comum entre o vulgo" o que, segundo a mesma autora, pressupõe formas de comunicação simples e acessíveis.

Apresentar um conjunto de objetos em um local público não é o suficiente para torná-los compreensíveis. Por outro lado, dar sentido não é diretamente proporcional à quantidade de textos apresentados em pôsteres, cartazes e até catálogos. Como já ressaltado por Davallon ${ }^{23}$, o sentido nasce também da disposição, cenarização, do uso de esquemas, fotografias e outras ferramentas de comunicação, visuais ou não. Ainda segundo o autor, esta natureza semiótica das exposições interessa especialmente aos museus de ciências, que visam a fazer com que o público descubra um mundo que the é desconhecido, adquira eventualmente algum conhecimento e, possivelmente, forme uma opinião sobre determinado assunto.

Referindo-se também à relação entre o museu e seus diversos públicos, Valente, Cazelli e Alves ${ }^{24}$ consideram, como inerente a ela, a dimensão educacional, à qual veio se somar, mais recentemente, a comunicação. $\grave{A}$ comunicação através das exposições, as autoras atribuem a função de mediação facilitadora entre o público e o saber ${ }^{25}$. A expografia torna-se, então, ferramenta essencial na comunicação do museu com a sociedade e na efetividade do processo de divulgação. Mas, como se dá a comunicação nestes espaços?

A expografia como ferramenta de comunicação/divulgação:

o caso dos museus de ciências 
Ao assumir, para suas exposições, um papel de divulgação do conhecimento à sociedade, o museu também assume a "sociedade" como seu público-alvo. E, uma vez que esse é representado pelo grande leque da "sociedade", as estratégias de divulgação do museu podem ser consideradas mecanismos de comunicação de massa.

Vale ressaltar, com relação a esse ponto, que a comunicação de massa é tida como uma "comunicação não-natural". Hooper-Greenhill26 a define assim, por se tratar de uma comunicação à distância e realizada, geralmente, na ausência de uma das duas partes envolvidas no processo. Hodge e D'Souza ${ }^{27}$ exemplificam que uma conversa face a face seria uma típica "comunicação natural". Em oposição, explicam que o sistema de "comunicação não-natural" não pode contar com os auxílios de diversas ferramentas como a entonação, gestos e expressões, tão usuais na "comunicação natural". Por outro lado, Hooper-Greenhill28 destaca que as formas de comunicação dos museus são extremamente variadas e que isto é seguramente um de seus grandes trunfos em relação a outras mídias de massa.

Cury $^{29}$ reforça dizendo que comunicação museológica é uma denominação genérica que pode ser dada às diversas formas de extroversão do conhecimento em museus, como artigos científicos versando sobre estudo de coleções, catálogos, materiais didáticos em geral, vídeos e filmes, palestras e oficinas. Segundo essa autora, todas são estratégias de comunicação, mas as exposições são a principal ou a mais específica forma de comunicação de um museu.

Assim, embora a variedade de estratégias comunicativas a que se referem Hooper-Greenhill e Cury ${ }^{30}$ não se limite à exposição, parece-nos de alta importância analisar as diferentes formas de expor nos museus uma vez que este é o seu meio de comunicação por excelência e conseqüentemente o grande diferencial destas instituições.

De acordo com La museologie selon Georges Henri Rivière ${ }^{31}$, as formas de exposição das coleções (a partir dos Gabinetes de Curiosidades até os mais modernos museus) têm sido consideradas objetos de estudo. $\bigcirc$ autor faz um rápido levantamento dos grandes passos dessas estratégias para valorização das coleções da "caverna de Ali Babá" (com sua característica e aparentemente desordenada acumulação de objetos), às diferentes formas de classificação, e conseqüente especialização dos museus. No processo, menciona o surgimento das vitrinas, a passagem da panóplia le do princípio de exaustiva apresentação de objetos idênticos) à escolha de exemplarestipo ou modelos de uma série, a invenção das reconstituições caracterizadas na história natural pelos dioramas, o uso de maquetes e modelos, e a interatividade ${ }^{32}$, tida hoje como inovadora, embora date de mais de cem anos. Outra importante mudança é a expansão das exposições para fora de seu espaço tradicional, com as exposições itinerantes e o nascimento dos ecomuseus. Por fim, Rivière ${ }^{33}$ lembra que os diferentes métodos de exposição citados não são mutuamente exclusivos, e que, na
26. Cf. Eilean Hooper-Greenhill (1999, p. 28)

27. Cf. Robert Hodge \& Wilfred D'Souza (1999, p. 53)

28. Cf. Eilean Hooper-Greenhill (1999, p. 29)

29. Cf. Marília Xavier Cury (2005, p. 35).

30. Ver . Eilean Hooper-Greenhill (1999) e Marília Xavier Cury (2005)

31. Cf. Georges Henri Rivière (1989, p. 88II). Esta obra conta com inserção de cadernos de ilustrações, não paginados. O citado aqui está disposto entre as páginas 88 e 89 . As autoras do presente tomaram a liberdade de numerar suas páginas com algarismos romanos, estratagema que será repetido nas próximas citações da obra.

32. Embora os estudos sobre interatividade, como será apontado adiante no texto, considerem diversas modalidades de interação (contemplação pode ser um exemplo de interação), o autor refere-se aqui à interatividade através de manipulação. 
33. Cf. Georges Henri Rivière $(1989$, p. 88xxxII).

34. Ver Paulette M. McManus (1992).

35. Cf. Michel Van-Praët (1989, p. 26).

36. Cf. Paulette M. McManus (1992, p. 159).

37. Cf. Michel Van-Praët (1989, p. 27).

38. Cf. Paulette M. McManus (1992, p. 161)

39. Ibidem.

40. Idem, p.162.

41. Cf. Michel Van-Praët (1989, p. 28).

42. Em geral, são chamadas de exposições interativas, as exposições manipulativas conforme será discutido adiante.

43. Cf. Paulette M. McManus (1992, p. 163).

44. Cf. Michel Van-Praët (1989, p. 29). composição de seus espaços expositivos, os museus de hoje fazem uso de uns e outros.

Voltando-se para os museus de ciências, McManus ${ }^{34}$ descreve três grandes gerações - que podem ser encontradas até hoje -, cada uma com suas implicações na museografia. Estas gerações são marcadas pelo desenvolvimento dos conhecimentos e da pesquisa na História Natural o que, segundo VanPraët ${ }^{35}$, teve profunda influência nas exposições. Derivada dos Gabinetes de Curiosidades, a primeira geração é caracterizada por McManus pela saturação de objetos, além de apresentar vínculos com a academia e a universidade ${ }^{36}$. Surgindo em meados do século XVIII, essa geração inclui grandes museus de história natural e museus voltados para coleções de instrumentos científicos. VanPraët, ao se referir à mesma geração de museus, explica que a exposição - até então um grande depósito de todas as riquezas coletadas - agora vê sua museografia norteada pelo desejo de classificação e organização: são as "galerias bibliotecas"37. Nos anos 1960-1970, esta geração ganhou um novo estágio de desenvolvimento, com a passagem da exposição taxonômica para aquelas de apresentação de conceitos científicos ${ }^{38}$.

A segunda geração de museus de ciências, segundo McManus ${ }^{39}$, foi estabelecida na virada do século XVIII para o XIX, para atender às necessidades das indústrias. Voltando-se para o mundo do trabalho e seus avanços tecnológicos, suas exposições, com caráter de demonstração, eram usadas na formação técnica daqueles trabalhadores que iriam operar as máquinas. Hoje voltada para o público em geral, essa geração de museus preservou em sua museografia elementos manipuláveis ${ }^{40}$, embora ao retratar, por meio de artefatos, o desenvolvimento tecnológico, apresente um caráter histórico. Nos museus de história natural, esta geração é marcada, segundo Van-Praët ${ }^{41}$, pelas exposições temáticas com vocação didática. Tais exposições respondem às teorias surgidas em ciências até então descritivas e classificatórias. Aqui começa a separação entre a pesquisa que é feita e a exposição que se apresenta: as galerias perdem seu caráter de bibliotecas e tornam-se, cada vez mais, espaços de comunicação.

Na terceira geração, datada da década de 1930, McManus indica que as idéias substituem os objetos, ou seja, a preocupação que vigorava era com a transmissão de conceitos científicos, mais do que com a contemplação de objetos ou com a história do desenvolvimento científico. A ênfase, nestes casos, é na ciência e tecnologia contemporânea, por meio de exposições interativas ${ }^{42}$. Esta geração de museus dá origem, entre outros, aos atuais centros de ciências ${ }^{43}$.

Os anos 1930 marcam o começo da afirmação da ecologia e a conseqüente imposição de uma nova temática nos museus de história natural, levando à adoção da técnica dos dioramas ${ }^{44}$. É nesta época que o duque de Orléans, concebe o primeiro museu de dioramas de história natural. Nos jardins botânicos também se vê a substituição da organização classificatória por organizações temáticas ${ }^{45}$. Entre 1935 e 1938, no Jardin des plantes du Museum, 
em Paris, são criados o Jardim Alpino, o Parque Ecológico lapresentando associações vegetais originárias da llle-de-France) e a Grande Estufa (apresentando exemplares da região tropical úmida). Estas novas tendências resultam na separação definitiva entre o processo de pesquisa e a exposição. Van-Praët46 ressalta que a exposição não mais permite que o visitante faça, por meio de objetos autênticos, as mesmas observações que levaram o pesquisador às suas conclusões, mas fornece-lhe, de forma atrativa, as conclusões lecológicas, por exemplo) do idealizador da mostra.

Por outro lado, para o final do século XX, Rivière distingue quatro grandes tipos de museus: museus de arte, museus das ciências do homem, museus das ciências da natureza, e museus de ciência e tecnologia ${ }^{47}$. Nem sempre esta divisão é tão categórica, e, da sobreposição destas áreas, surgem os museus multidisciplinares e os interdisciplinares. Os primeiros são definidos como mistos ou pluridisciplinares (lembrando um aglomerado de museus unidisciplinares onde nenhuma relação é estabelecida entre as diferentes áreas). Já os museus interdisciplinares são definidos como aqueles concebidos em torno de um tema único, tratado sob diferentes perspectivas. Rivière ${ }^{48}$ destaca que estes últimos, ao seguirem uma vertente biográfica ou monográfica, podem tornar-se museus especializados, e aponta dois outros pares de classes em que as exposições podem ser divididas: ecológicas ou sistemáticas, e culturais ou científicas, destacando que as duas tendências podem ser mescladas, tornando uma exposição mais dinâmica.

No mais, Alexander explica que as exposições dos museus podem ser montadas a partir de dois grandes modelos: as exposições permanentes e as temporárias. A divisão do autor pode nos parecer óbvia e até primária, mas logo ele elucida que a museografia da exposição pode ser muito diferente se for concebida como permanente ou como temporária. Cita, por exemplo, que a última categoria pode vir a fazer uso de técnicas mais teatrais, para passar sua mensagem mais rapidamente, já que provavelmente será vista uma única vez pelo público ${ }^{49}$.

Todas essas opções dão origem a fatores que podem ser analisados com relação à comunicação e suas estratégias na expografia praticada nos museus. Para esta nossa reflexão, foram selecionadas três temáticas que serão discutidas a seguir e cujas aplicações permitem o estabelecimento de critérios para análise das exposições em museus de ciências. Exemplos das aplicações de cada uma das temáticas abordadas serão apontados na exposição de longa duração Pesquisa em Zoologia: a biodiversidade sob o olhar do zoólogo, inaugurada pelo Museu de Zoologia da Universidade de São Paulo em setembro de 2002. Desde então, essa exposição vem sofrendo alterações, algumas bem importantes do ponto de vista expográfico, mas sem mudanças conceituais no seu plano geral. Os objetivos comunicacionais da exposição em análise estão estruturados em quatro grandes módulos (Figura 1) que podem ser descritos sucintamente por seus títulos: Apresentação e história do Museu de Zoologia da
45. Ibidem.

46. Idem, p. 30.

47. Cf. Georges Henri Rivière (1989, p. 90).

48. Idem, p. 130.

49. Cf. Edward P. Alexander (1979, p. 176). 
50. Idem.

51. Cf. Georges Henri Rivière (1989).

52. Ver David Dean (2003).

53. Ver Jean Davallon (1986; 1989).
USP; Origem das espécies e dos grandes grupos biológicos; Evolução, diversidade e filogenia: atividades do zoólogo; e Fauna neotropical e ambiente marinho.

Tipos de exposição

Optou-se, aqui, por não discutir mais profundamente as categorias de exposição e/ ou museu mencionadas anteriormente, com base nos trabalhos de Alexander ${ }^{50}$ e Rivière ${ }^{51}$, e sim aquelas descritas por Dean ${ }^{52}$ e Davallon ${ }^{53}$.

Em seu trabalho, Dean ${ }^{54}$ define dois grandes tipos de exposições: as exposições educativas e as exposições temáticas. Para estabelecer tal

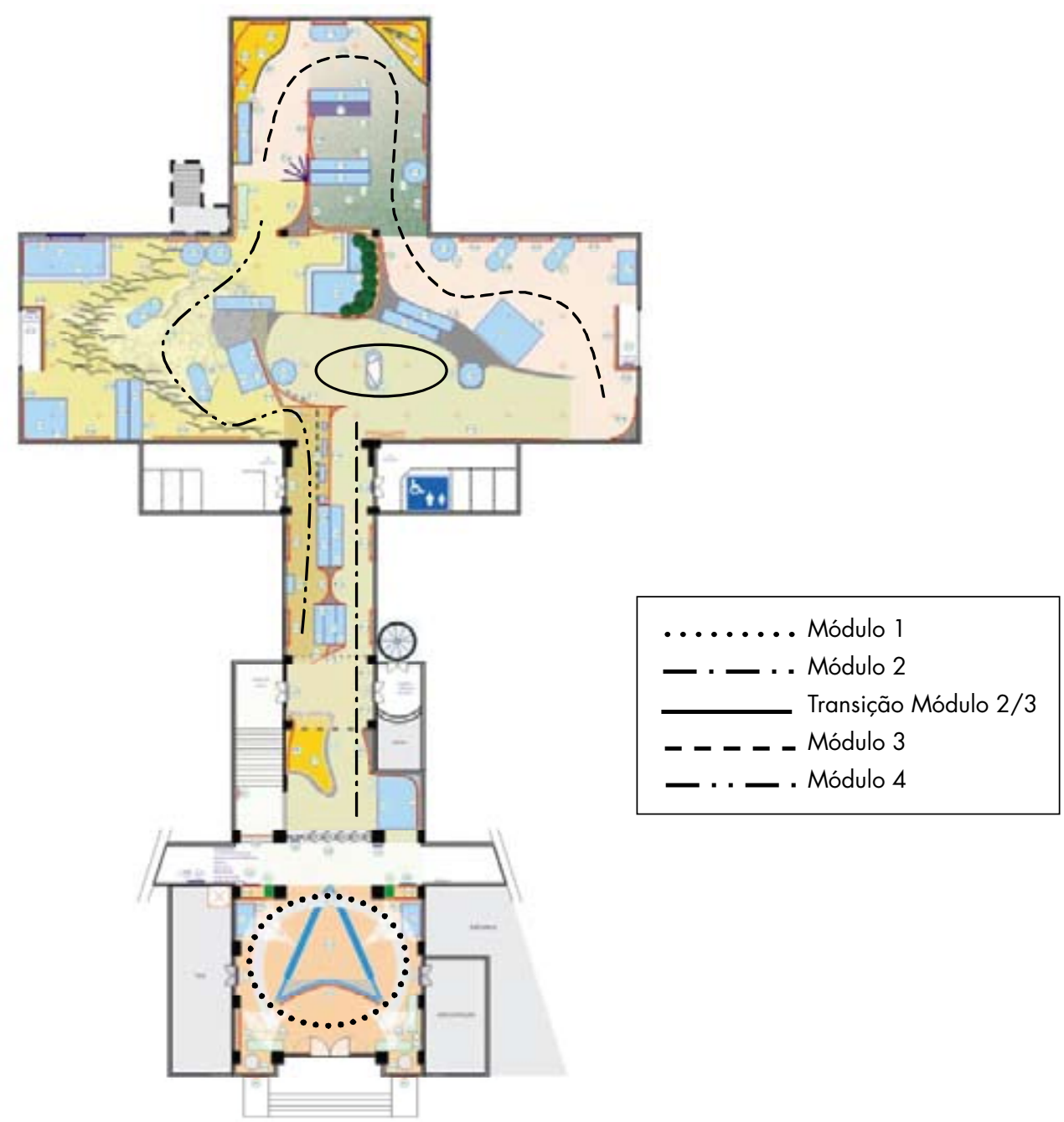

Figura 1 - Planta baixa da exposição de longa duração do Museu de Zoologia da USP, versão inaugural; original fornecido pelo Serviço de Museografia da Divisão de Difusão Cultural do Museu de Zoologia da USP; legendas das autoras. 
classificação, o autor indica que uma exposição se baseia em dois elementos: o objeto e o conceito.

Se o objeto é o elemento principal, tem-se o que ele chama de um display ${ }^{55}$ de objetos, onde os exemplares estão dispostos segundo padrões como, por exemplo, a estética. Neste modelo, considera-se que o objeto fala por si só, sem necessidade de qualquer informação interpretativa ${ }^{56}$. Um exemplo deste tipo de display é a exibição, geralmente em casa, de coleções cuja função é tornar o ambiente agradável e acolhedor.

No caso de a exposição ter como foco principal o conceito, o papel do texto passa a ser central, e tem-se o que Dean chama de um display de informações ${ }^{57}$. Neste caso, objetos podem não estar presentes ou são de mínima importância. Aqui a compreensão baseia-se muito mais no texto e nos elementos gráficos. Os objetos, quando presentes, são elementos completares que visam a facilitar a compreensão e ilustrar o conceito exposto, e não mais o eixo central.

$\mathrm{Se}$, a partir desses dois extremos, for traçado um gráfico (Figura 2) em que a tendência ao foco nos objetos ou nos conceitos for medida em porcentagens, obtém-se todo o gradiente possível de tipos de exposições.

Em uma extremidade, quando o eixo central é o objeto, estão as exposições temáticas onde as informações complementares que podem ser encontradas limitam-se ao básico, como nome do objeto e sua datação, por exemplo. As coleções são selecionadas e expostas por temas e sua apresentação é orientada diretamente por valores estéticos ou abordagens classificatórias. São exemplos claros deste tipo de exposição algumas vitrinas encontradas no Museu de Zoologia da USP, em que a preponderância é de objetos, como a vitrina Diversidade de moluscos, em que os espécimes estão dispostos acompanhados apenas de sua legenda de identificação (Figura 3).
54. Cf. David Dean (2003, p. $5)$.

55. David Dean (2003, p.3) define "display" como a apresentação pública de objetos sem acréscimo de interpretação significante.

56. Idem, p. 4

57. Ibidem.

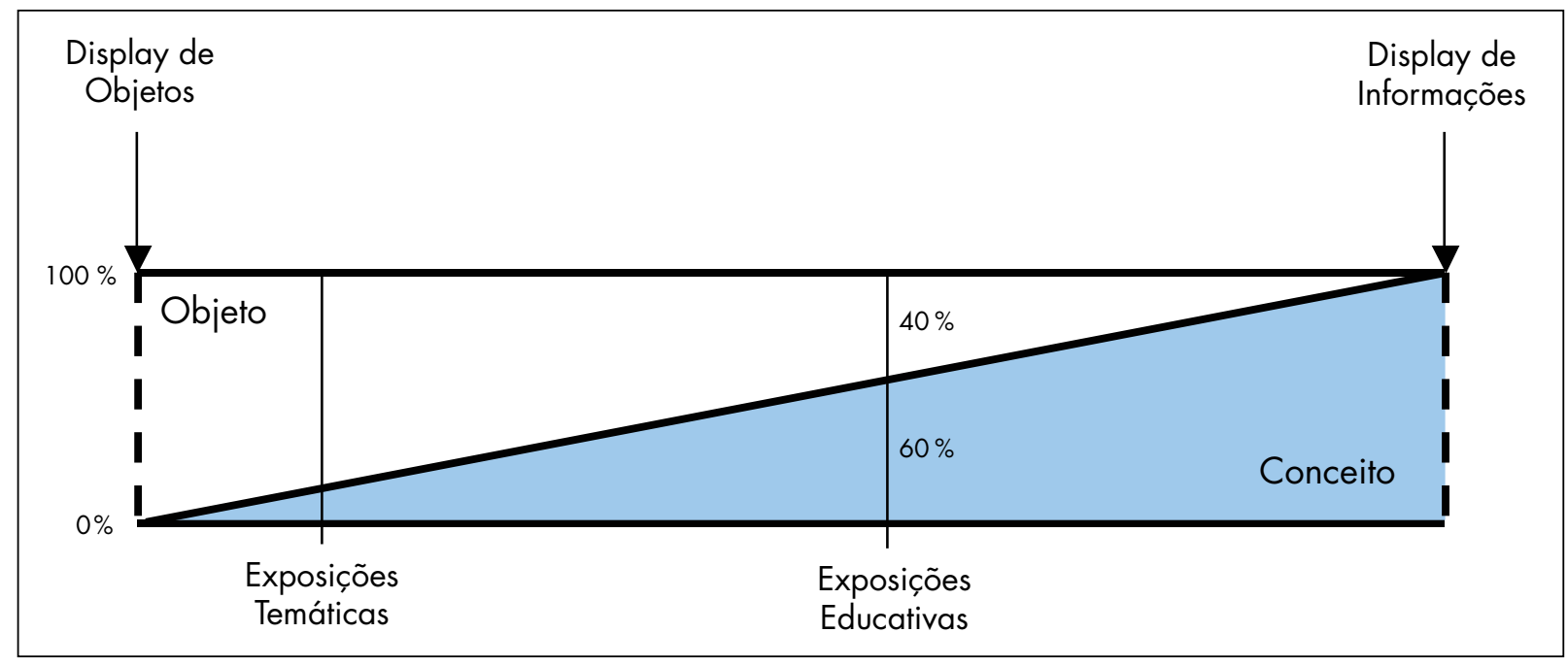

Figura 2 - Representação gráfica do gradiente de tipos de exposições. Adaptado de Dean (2003). 
No outro extremo, o conceito é que está em foco e o importante é a mensagem/informação. O objetivo é proporcionar a apreensão do conceito, e o fato de existir, ou não, uma coleção que auxilie na sua compreensão, ou o ilustre, é secundário. Nas exposições educativas, embora o objeto esteja presente (são compostas de cerca $40 \%$ objeto e $60 \%$ informação), os textos são essenciais para a compreensão da proposta da exposição. Exemplos de vitrinas em que o foco central é o conceito também são passíveis de serem observados na instituição paulista, como a vitrina Convergência evolutiva, em que exemplares de diferentes grupos animais auxiliam na compreensão do referido mecanismo de formação de espécies (Figura 4).

Vale ressaltar que não existe uma delimitação clara, uma linha que separe distintamente um tipo de exposição do outro.

No entanto, pode ser preocupante o uso que se faz de um ou outro tipo de display. Em seu trabalho, Wittlin ${ }^{58}$ define dois grandes grupos de problemas resultantes do design inapropriado de algumas exposições, que chama de displays "underinterpretive"59 e "misinterpretive"60.

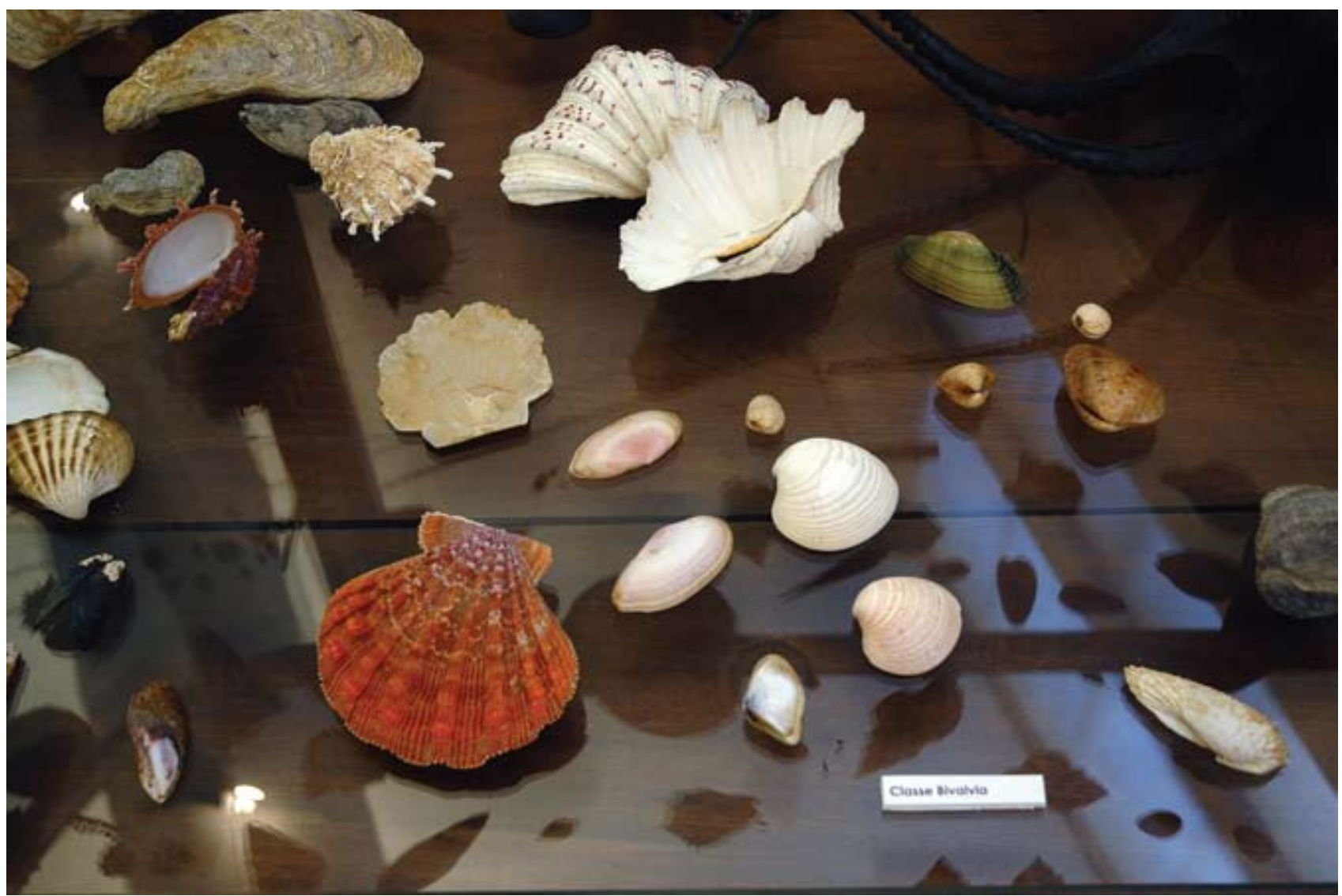

Figura 3 - Vitrina Diversidade de moluscos, exemplo de display predominantemente de objetos, Museu de Zoologia da USP, São Paulo. Fotografia de José Rosael, 2008. 


\section{Convergência evolutiva}

A convergência evolutiva é o fenômeno de haver espécies parecidas mas que não são parentes entre si.

Os animais de um mesmo grupo têm variaçōes genéticas e todos enfrentam uma pressão ambiental para viver. Sobrevivem e deixam descendentes aqueles que melhor conseguem explorar o ambiente onde vivem. Seus descendentes, depois de muitas geraçōes, podem ser bastante diferentes dos ancestrais.

Vários grupos de animais viveram em ambientes parecidos. Hoje encontramos os descendentes desses vários grupos já muito diferentes dos ancestrais, mas tendo características parecidas entre si!

As semelhanças sāo explicadas como resultado de modificações adaptadas (= ajustadas) a pressōes ambientais parecidas.

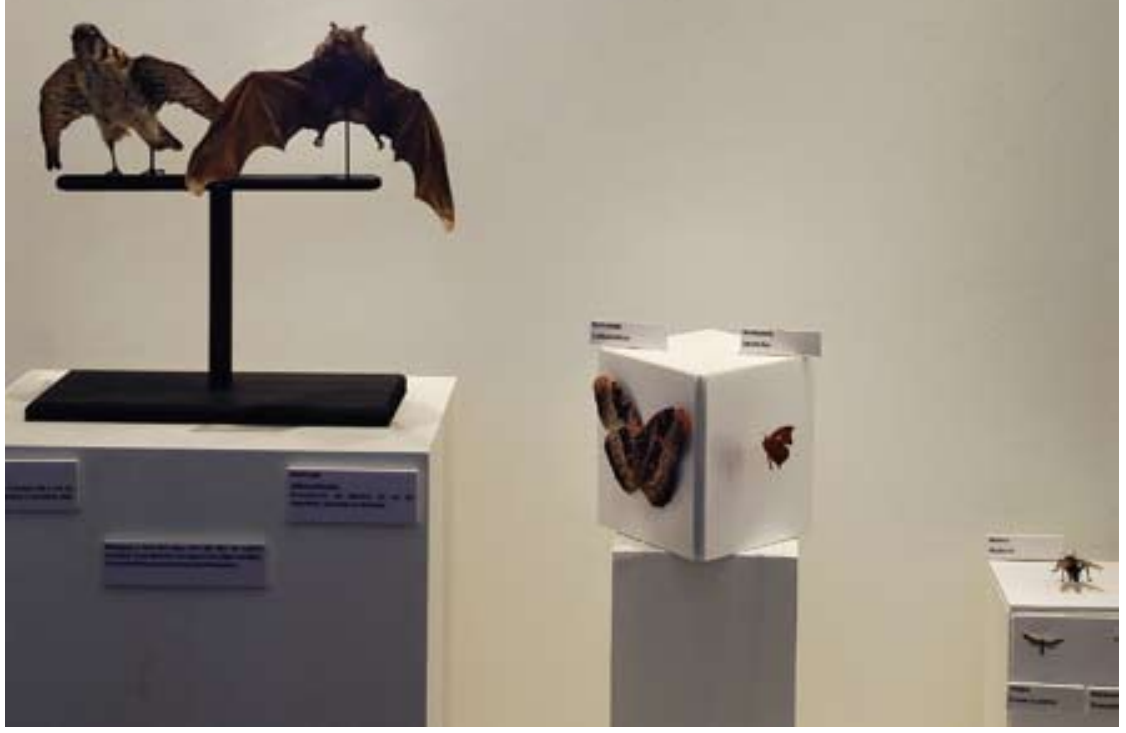

Figura 4 - Vitrina Convergência evolutiva, exemplo de display em que o foco é o conceito-título da mesma e não os objetos que a compõem, Museu de Zoologia da USP, São Paulo. Fotografia de José Rosael, 2008.

Os primeiros ("underinterpretive") são aqueles em que se acredita que os objetos possam falar por si sós. São exemplos as grandes vitrinas em que se expõem dezenas de exemplares biológicos lado a lado, sem qualquer recurso interpretativo ou com informações próximas às dos manuais de ensino. Neste caso, a montagem apresenta significado apenas para um especialista, enquanto o visitante leigo pode até identificar diferenças entre os objetos ou agrupamentos
58. Alma S. Wittlin (1971) apud Roger S. Miles (1988, p. 65).

59. Que induz a uma interpretação da informação abaixo do esperado.

60. Que induz a uma má interpretação da informação. 
61. Alma S. Wittlin (1971) apud Roger S. Miles (1988, p. 65)

62. Cf. Tony Bennett (2001, p. 28) entre eles sem, no entanto, poder levar o raciocínio adiante, e concluir, até, que a montagem é monótona visualmente, causando até certa perplexidade ${ }^{61}$. São exemplos desse tipo de display, na exposição do Museu de Zoologia, a já citada vitrina Diversidade de moluscos (Figura 3) e a vitrina Diversidade de invertebrados do cerrado brasileiro, em que os espécimes estão desacompanhados de qualquer informação, inclusive de legenda (Figura 5).

Esta questão já havia sido apontada como digna de preocupação, na década de 1890, pelo barão Osten Sacken, que advertiu o American Museum of Natural History a respeito da apresentação de numerosos objetos em uma mesma vitrine. Ele explica que o leigo é perfeitamente capaz de comparar e perceber as diferenças entre uma águia e um falcão, mas, se tem pela frente cem exemplares de águias e falcões, diferentes em tamanho, cor, origem, ele certamente não verá nada e não se lembrará de nada ${ }^{62}$.

Por outro lado, as montagens "misinterpretive" descritas por Wittlin são aquelas que combinam uma superestimulação sensorial com um déficit intelectual, ou seja, idéia e objeto são tratados juntos, como uma experiência visual, voltando-se a atenção do visitante apenas para o arranjo estético ${ }^{63}$. É o caso de modelos reproduzidos em dimensões ou com abstração tamanha que não são mais reconhecidos, e o visitante, embora fascinado, sai desinformado64. $\mathrm{Na}$

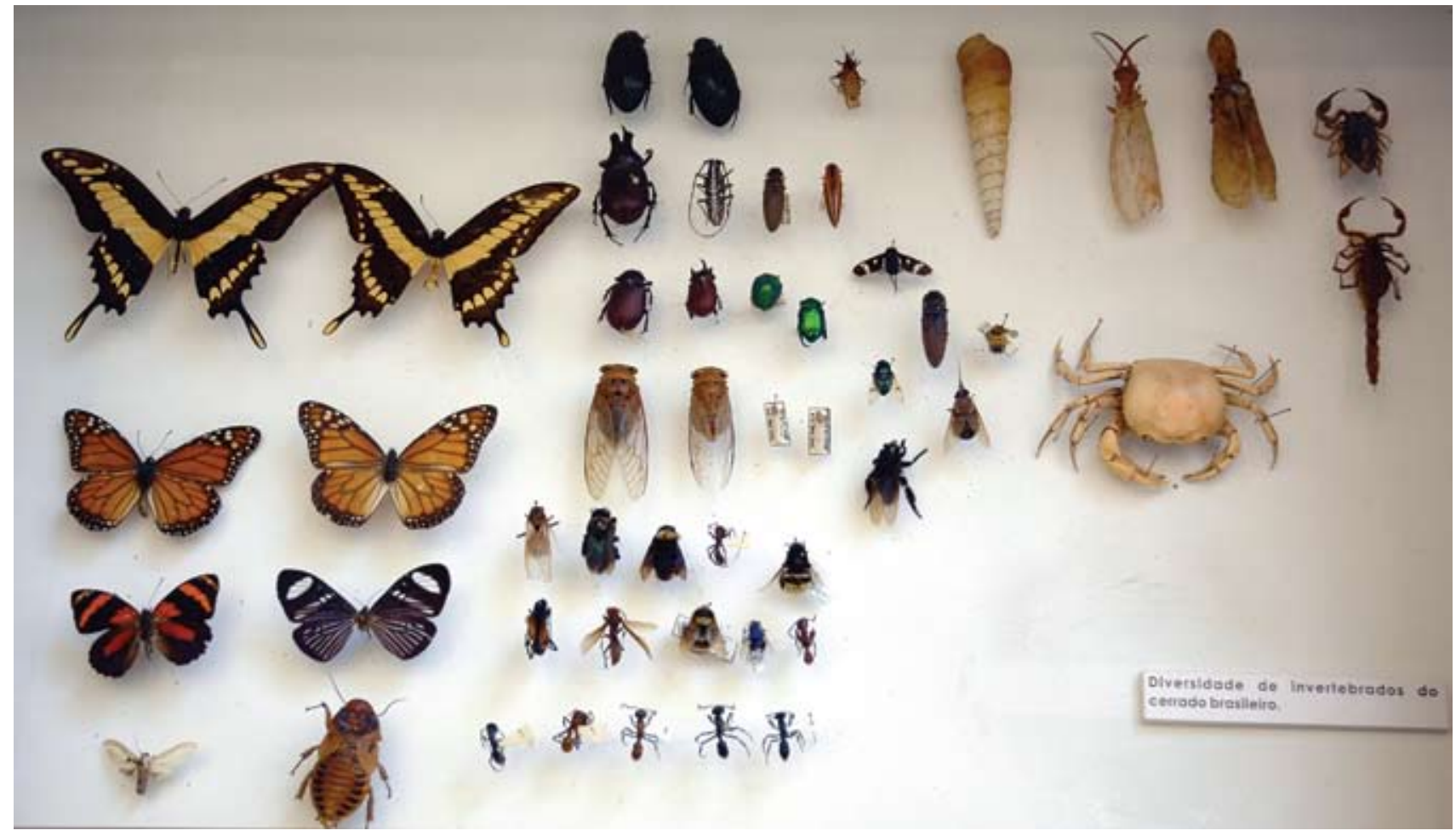

Figura 5 - Vitrina Diversidade de invertebrados do cerrado brasileiro, exemplo de display underinterpretive, Museu de Zoologia da USP, São Paulo. Fotografia de José Rosael, 2008. 
exposição do Museu de Zoologia da USP, é exemplo desse tipo de display o da A árvore da vida (Figura 6), pois, apesar de acompanhado por um texto que explica seu sentido geral, o display, por suas características, é visualmente muito atrativo, sem que se possa, porém, compreender a significação de todas as opções de sua conformação (ramos, diferenciações de cores etc.).

Davallon, por sua vez, comenta ${ }^{65}$ que as exposições em geral, embora aparentemente muito diversas, poderiam ser classificadas em três grandes

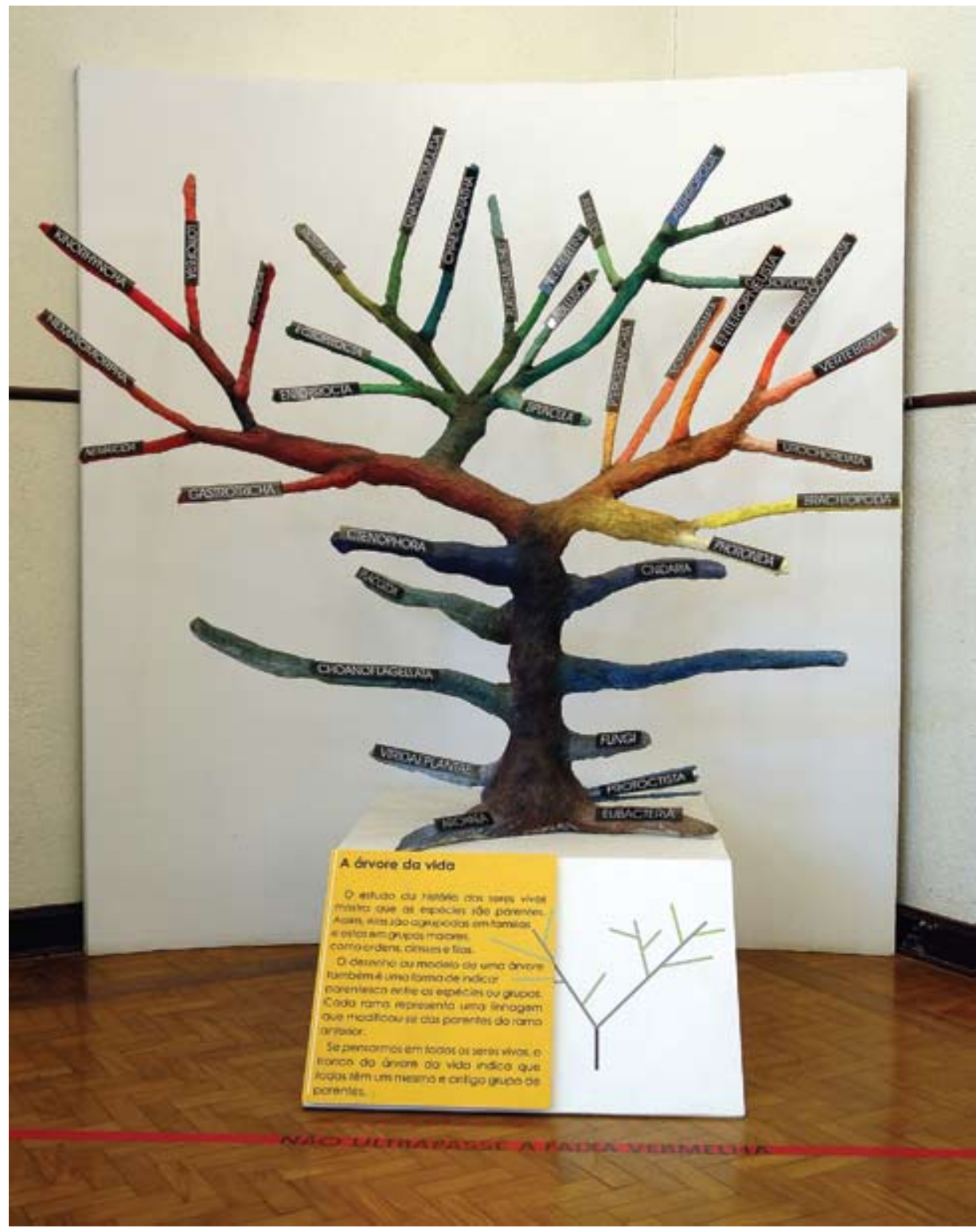

Figura 6 - A árvore da vida, exemplo de display misinterpretive, Museu de Zoologia da USP, São Paulo. Fotografia de José Rosael, 2008.
63. Alma S. Wittlin (1971) apud Roger S. Miles (1988, p. 66).

64. Ibidem. 
65. Cf. Jean Davallon (1986, p. 8).

66. Idem, p. 8-9.

67. Cf. Jean Davallon (1989, p. 50)

68. Idem, p. 57 categorias, concebidas com base nos objetivos a elas atribuídos pelos que as montam ou as encomendam - ou seja, é uma classificação estabelecida a partir do ponto de vista do produtor. Cada uma delas apresentaria traços museográficos característicos. A primeira seria a das exposições que propõem uma situação de encontro do visitante com objetos, ou seja, onde a prioridade é permitir ao visitante ver, contemplar, estar "em contato" com os objetos. Neste tipo de exposição, a técnica expositiva é a mais discreta possível, de forma a não distrair o olhar do visitante quando da contemplação da obra. A segunda categoria concentraria exposições que se fazem vetores de uma estratégia de comunicação e, nelas, todo o cuidado se voltaria para a cenarização e apresentação dos objetos, pois precisa, a qualquer custo, passar uma mensagem. Neste grupo estariam concentradas as exposições de objetivo didático, sejam elas científicas, técnicas ou culturais. Por fim, a terceira categoria seria a das exposições que visam a um impacto social e que têm como característica mais marcante a proximidade que propõem, expõem e com a qual trabalham, entre o tema e/ ou os objetos e o público. Este tipo de exposição parece dizer ao público: "olhe o que eu the mostro, pois não the é estranho, é sua região, sua cidade, seu emprego ou o dos seus, é o seu grupo"b6.

Seguindo o raciocínio das exposições com base no objetivo com que foram concebidas, Davallon ${ }^{67}$, ao tratar especificamente das exposições de cunho científico, ressalta que haveria um mal-entendido quanto aos objetivos para os quais essas deveriam ser concebidas. A seu ver, deveriam ser mais uma ferramenta para a instauração de uma relação entre público e ciência (terceira categoria) do que uma forma de transmissão de conteúdos científicos (segunda categoria). Assim, para o autor, as exposições poderiam ser consideradas de acordo com o tipo de relação do público com a ciência ou o saber que venham a despertar (relação "mágica", "utilitária", "cultural", "esotérica", "estética" ou até um misto desses tipos).

Tais tipos de relação do público com a ciência seriam decorrentes do processo sofrido pelo saber científico ao ser transformado em comunicação pública. $\bigcirc$ mesmo Davallon ${ }^{68}$ defende que a análise desse processo permitiria distinguir de forma mais apurada os diferentes tipos de exposição. Segundo ele, há exposições que guardam forte relação com os textos científicos e cuja apresentação faz uso, inclusive, de métodos similares àqueles utilizados tradicionalmente no ensino de ciências, como nos livros e modelos didáticos; tal tipo de exposição supõe uma grande cooperação do visitante lem termos de aporte de conhecimento prévio), para que se opere uma significação. Há também exposições em que é dado um tratamento mais figurativo, situação que, se for levada ao extremo, conduz a exposições enciclopédicas: uma coleção de peças expositivas referindo-se a um processo, uma lei, um fenômeno etc.

Por outro lado, se é dado um importante tratamento narrativo, orientase para a exposição-espetáculo (som e luz, reconstituições etc.) ou para o aumento da solicitação do visitante enquanto ator, com a implantação de 
unidades interativas e/ou uma organização espacial da exposição, de modo a torná-la equivalente a uma narração.

Estes exemplos permitem perceber o que o autor chama de uma das oposições mais evidentes, a saber, aquela que permite distinguir a significação centrada nos conceitos científicos daquela centrada na relação com as questões da ciência de maneira mais ampla69. Essas duas significações podem ser encontradas nas exposições, ora tendendo para uma delas, ora para a outra, não sendo, nenhuma das montagens conseqüentes, sinônima de eficácia comunicacional.

Davallon, ainda, descreve a comunicação como um processo intencional de informação (há uma vontade de informar), indissociável de uma conseqüente estratégia (consciente e deliberada) de comunicação que, no caso da museografia das exposições de ciências, visaria, em geral, a suscitar a descoberta e a compreensão do saber ${ }^{70}$. Além desta estratégia, que chama de "estratégia comunicacional", o autor define dois outros tipos que também teriam relação direta com os estilos de montagem expositiva. Uma delas seria a "estratégia estética", que visa a tornar o objeto exposto um "objeto revelado" ao público, caso freqüente, segundo o autor, em história e arqueologia, mas também quando da exposição de técnicas e máquinas. A outra seria a "estratégia lúdica", tendo por objetivo transportar o visitante tanto no sentido literal quanto no figurado, o que é comum em exposições onde a interatividade se manifesta no exercício da manipulação.

É com base nessas estratégias e de acordo com a forma - erudita, lúdica, estética, cultural, mágica ou interativa - com que as exposições se propõem a abordar a ciência que o autor sugere que deva se dar a análise das montagens expositivas ${ }^{71}$.

Se compararmos as estratégias comunicacionais discutidas por Dean e Davallon, podemos estabelecer uma relação entre o "display de objetos", de Dean, e a "estratégia estética", de Davallon, já que ambos consideram o objeto como ponto central. Também é possível aproximar a "estratégia comunicativa", de Davallon, dos "displays de informação", de Dean, uma vez que os dois lidam preponderantemente com conceitos e conhecimentos científicos. As estratégias "estética" e "comunicativa" poderiam, portanto, ser exemplificadas pelas mesmas vitrinas da exposição do Museu de Zoologia, a saber, aquelas representadas, respectivamente, na Figura 3 e na Figura 4.

Por outro lado, a "estratégia lúdica" exposta por Davallon não aparece na proposta de Dean. Entendemos não haver, no Museu de Zoologia, montagem que claramente exemplifique tal estratégia ${ }^{72}$.

Ao levarmos em conta os dois pontos comuns das propostas de Dean e Davallon podemos nos perguntar, no caso de ter a exposição, como eixo central, conceitos ou saberes e desenvolver-se a partir de textos preponderantemente impressos, se não se tornaria, então, um grande livro tridimensional?

Davallon ressalta que a exposição faz "ver", mas, para fazer "conhecer", deve responder a uma estratégia de comunicação que leve em conta
69. Idem, p. 56.

70. Ibidem.

71. Idem, p. 57.

72. Sabemos que o Serviço Educativo do Museu de Zoologia desenvolve atividades lúdicas relacionadas à exposição. No entanto, elas não fazem parte da montagem expográfica. 
73. Cf. Jean Davallon (1989, p. 50$)$.

74. Cf. Robert Hodge \& Wilfred D'Souza (1999, p. 57).

75. Cf. Michel Van-Praët (1989, p. 32).

76. Cf. Marília Xavier Cury (2005, p. 46).

77. Cf. Robert Hodge \& Wilfred D'Souza (1999, p. 58).

78. Cf. Peter Vergo (1989, p. 48) as características do espaço-museu e das transformações que tais características imprimem aos conteúdos científicos, e não a uma estratégia que assemelhe o funcionamento semiótico das exposições àquele de livros, do cinema, do ensino ou de outras mídias ${ }^{73}$. Hodge e D'Souza frisam o fato de a mensagem comunicada pelos displays nos museus acontecer de diferentes formas e fazendo uso de variadas mídias, tais como objetos e artefatos, simulações de ambientes, fotografias, diagramas, legendas e textos ${ }^{74}$. Muitas dessas mídias são comuns a diferentes meios de divulgação, mas entendemos que, de forma geral, o objeto é o maior diferencial do museu frente aos outros meios de divulgação/ comunicação.

O objeto

objeto, segundo Van-Praët75, é um trunfo didático essencial para maravilhar, espantar, questionar, e é o que dá à exposição sua especificidade frente a outras mídias de divulgação. Cury acrescenta, ainda, que o objeto museológico é o elemento estruturador de uma exposição, seja para quem a concebe, seja para quem a visita e, portanto, deve ser enfatizado, em detrimento de outros recursos museográficos ${ }^{77}$.

No entanto, Hodge e D'Souza previnem que a comunicação através de objetos e artefatos, embora não deva ser subestimada - pois eles são potencialmente acessíveis a todos os sentidos (poderiam ser vistos, manipulados, cheirados e até experimentados) e comunicam perfeitamente o que são-, é uma das formas menos compreendidas de comunicação. $\bigcirc$ fato é que todas as informações cuja compreensão por si só o objeto permite estão destinadas a perder-se caso não forem codificadas em linguagem ${ }^{77}$.

É importante notar, aqui, o que Vergo já apontava como opiniões divergentes acerca do uso de objetos nas montagens expositivas. Em um extremo do leque de opiniões, o autor coloca os defensores daquelas que ele chama de exposições "estéticas", ou seja, uma exposição em que o processo de compreensão seria essencialmente uma comunhão particular entre o próprio visitante e o objeto exposto. Neste caso, texto e outras ferramentas de comunicação associadas ao objeto podem ser consideradas unicamente como um mal necessário, ou até mesmo como uma indiscreta intromissão em um momento particular de contemplação ${ }^{78}$. Vergo ainda aponta que, na outra extremidade, podemos encontrar advogados do que ele chama de exposições "contextuais", ou seja, aquelas em que os objetos expostos são tidos como de relativa baixa significância intrínseca se vistos puramente como objetos de contemplação. Sua presença nas exposições é, no entanto, justificada a partir do momento que passam a ser considerados como testemunhos, por exemplo, de uma época, de uma cultura, de um fenômeno ou processo. Aqui, objetos coexistem com diversos outros materiais - informativos, explicativos, comparativos - , a maioria deles na forma de linguagem escrita ${ }^{79}$. 
No mesmo sentido, embora acreditem que apenas a linguagem verbal (textual, sonora ou outra forma) seja um meio de comunicação auto-suficiente, Hodge e D'Souza defendem que museus devem recorrer a mais elementos que fotografias e textos, para não se tornarem livros tridimensionais ${ }^{80}$.

Jim Bennett, por sua vez, chama a atenção para o fato de que, por necessidades do design, as exposições têm se tornado minimalistas, com um número cada vez menor de objetos e, também, de material de apoio. A seu ver, tais exposições minimalistas não auxiliam na compreensão da ciência enquanto influência insidiosa e multifacetada na formação da cultura moderna, e acrescenta que, eventualmente, elas levarão ao solapamento do objetivo e da missão do museu $^{81}$.

Objeto real tem ferrenhos defensores, como Wagensberg (2000, p. 16) que explica que textos, imagens, jogos, simulações, cenografias e modelos, devem ser considerados acessórios e complementares, mas que a exposição deve basear-se no real ${ }^{82}$. $\bigcirc$ autor salienta que a ciência procura entender a realidade e que esta é composta por objetos e fenômenos; os últimos entendidos aqui como as mudanças experimentadas por objetos ${ }^{83}$. Isto significa que a realidade, seja na forma de objeto ou fenômeno, é um fator insubstituível nos museus de ciência, um "must-have". E o autor vai além, considerando o museu realidade concentrada ${ }^{84}$.

Alexander, por sua vez, defende que, para a montagem de uma exposição eficaz, deve-se fazer uso de objetos, preferencialmente originais ou pelo menos réplicas tridimensionais e/ou modelos. Isto porque, por estarem presentes no mundo desde muito antes da linguagem, quando apropriadamente arrumados têm o poder inato de comunicar e informar. Considerando os objetos como a essência dos museus, o autor expõe que montagens que fazem uso apenas de obras de arte, fotografias, etiquetas e dispositivos multimídia, podem ser confusas e de difícil memorização ${ }^{85}$. Completa, ainda, que, neste último caso, seria melhor se a equipe do museu investisse suas energias na produção de publicações ou de filmes que o público pudesse desfrutar confortavelmente instalado em uma poltrona, em casa ou em um auditório ${ }^{86}$. Essa idéia é retomada por Wagensberg ao afirmar que exposições sem uma parcela mínima de realidade são reduzidas a livros que se lê de pé ou a cinemas multiplex em uma só sala. Acrescenta que uma exposição pode ser considerada fraca se pode ser substituída, com vantagem e sem sair de casa, por um bom livro, um bom vídeo, uma boa conexão de internet: um visitante pode ir vê-la, mas provavelmente preferirá não ir ${ }^{87}$.

Miles considera que animais montados ou taxidermizados em posições ditas "naturais" se assemelham ao objeto real, embora o processo de preparação do animal permita uma primeira interpretação pelo taxidermista, uma vez que determinada pose pode ser estabelecida para ênfase de um comportamento específico ou de dada estrutura ${ }^{88}$. É o caso, por exemplo, das vitrinas do Museu de Zoologia que contrapõem Animais ativos durante o dia (Figura 7) a Animais ativos durante a noite (Figura 8).
79. Ibidem.

80. Cf. Robert Hodge \& Wilfred D'Souza (1999, p. 60).

81. Cf. Jim Bennett (2001, p. 174).

82. Cf. Jorge Wagensberg (2000, p. 16).

83. Cf. Jorge Wagensberg (2005, p. 310).

84. Ibidem.

85. Cf. Edward P. Alexander (1979, p. 178).

86. Ibidem.

87. Cf. Jorge Wagensberg (2005, p. 314). 
88. Cf. Roger S. Miles (1988, p. 84 )
Por outro lado, o mesmo autor considera os modelos como excelente solução para a apresentação de objetos tridimensionais que, em sua forma real, seriam muito pequenos, muito grandes ou impossíveis de utilizar por qualquer outra razão ${ }^{89}$. São uma opção muito flexível de apresentação já que permitem eliminar detalhes irrelevantes para o tema a que se remetem, evitando a distração do observador. Réplicas também podem ser consideradas modelos, embora, neste caso, nenhum detalhe seja suprimido, ou seja, são modelos fiéis. Podem

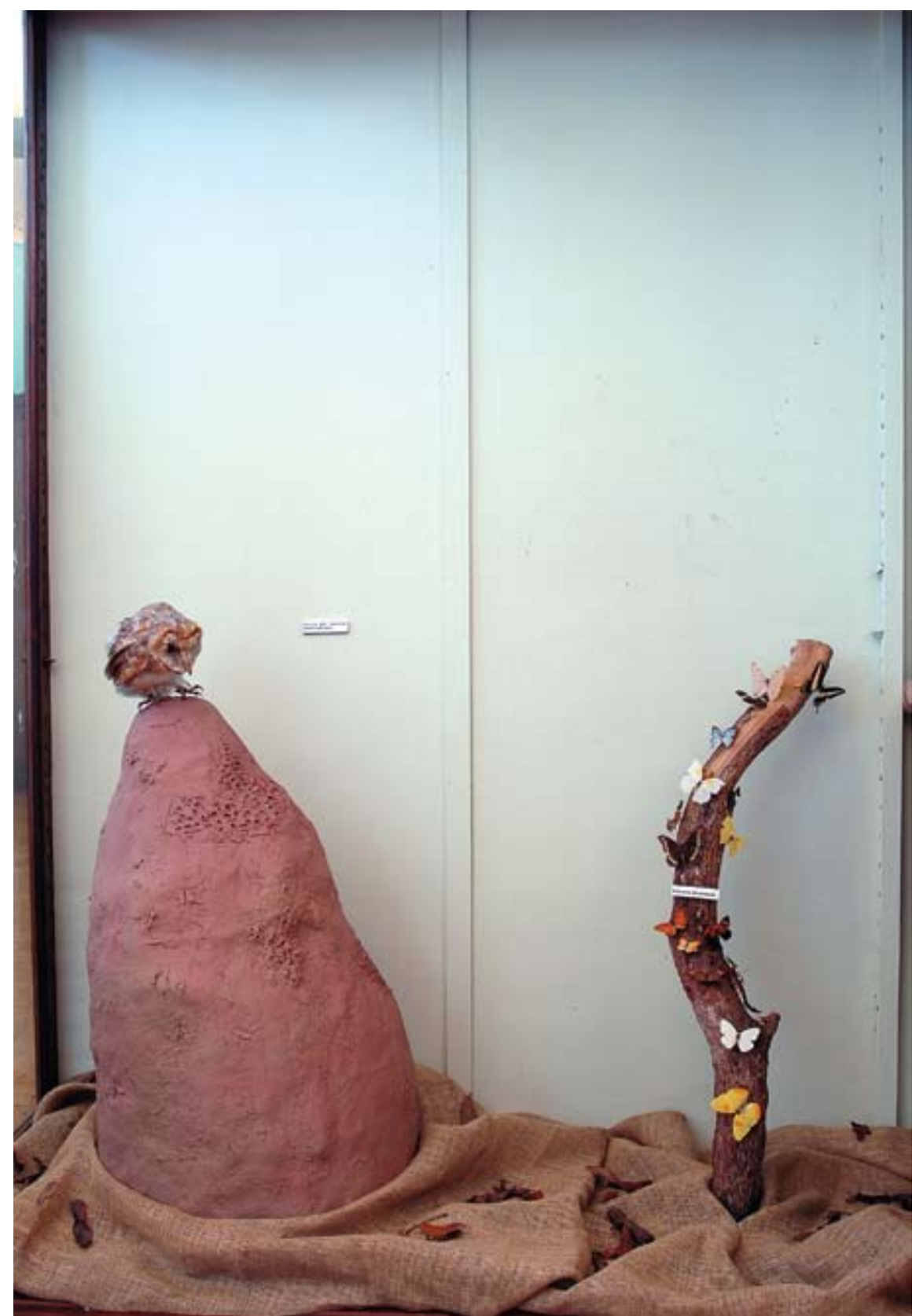


ser uma opção que, quando o objeto real é muito frágil ou valioso para ser 89. Idem, p. 83. apresentado em exposição, permite inclusive a manipulação. A técnica das réplicas é muito utilizada na apresentação de esqueletos de animais extintos, como no caso da preguiça-gigante e dos tigres-dente-de-sabre expostos no Museu de Zoologia, na vitrina Megafauna (Figura 9). Moluscos inteiros (animal e concha) são impossíveis de serem expostos em dioramas, por exemplo, já que a parte mole do animal não se conservaria. Para solucionar esta questão, o Museu

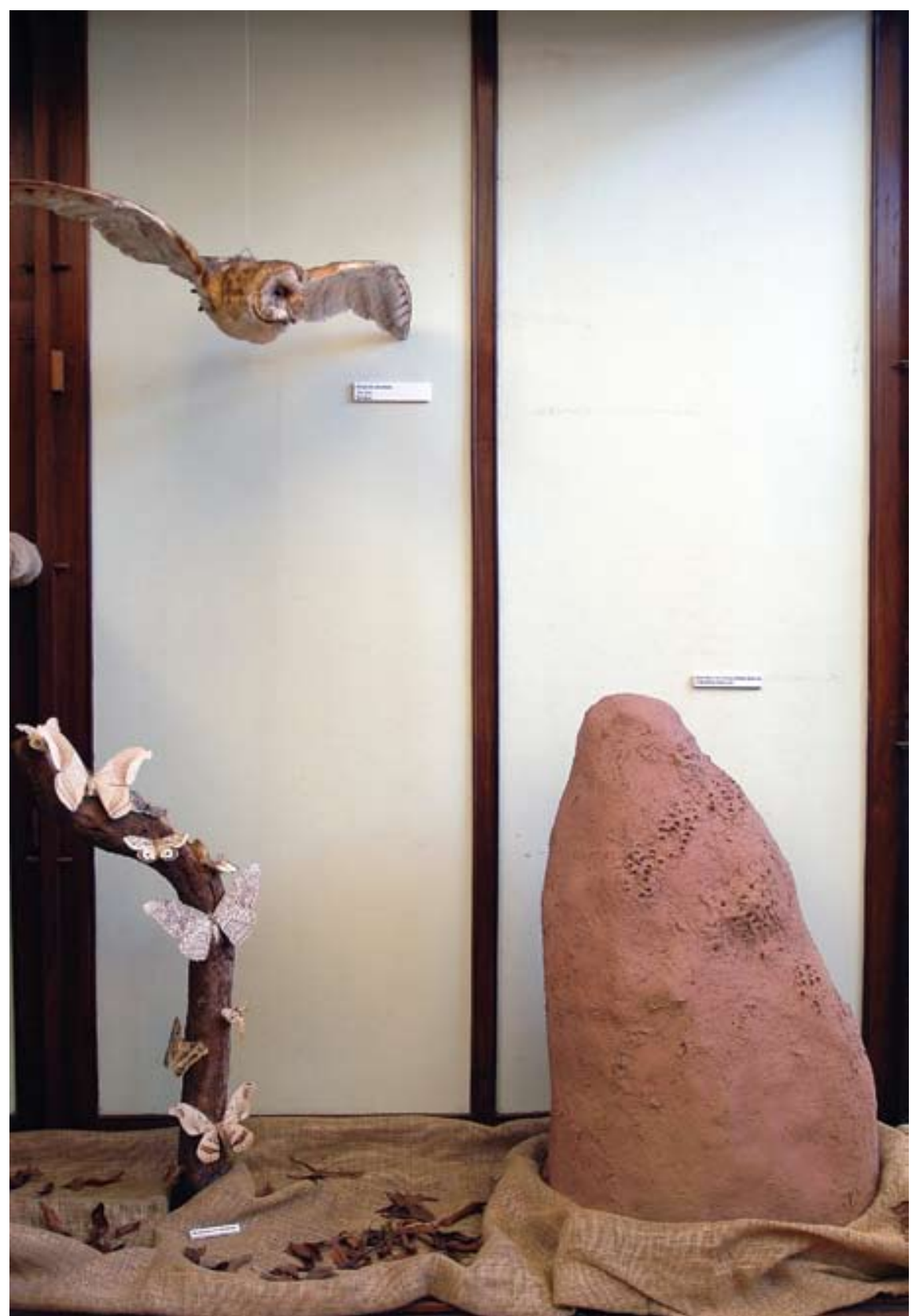

Figuras 7 e 8 - Animais ativos durante o dia, Animais ativos durante a noite, vitrinas exemplificando a montagem de animais taxidermizados dando ênfase a determinados comportamentos, Museu de Zoologia da USP, São Paulo. Fotografias de José Rosael, 2008.

Annals of Museu Paulista. v. 16. n.2. July - Dec. 2008 
de Zoologia, em sua vitrina Praias arenosas, recorreu a modelos, utilizando conchas reais e representando a parte mole em resina (Figuras 10 e 11 ). Outro exemplo que pode ser citado é o dos modelos que representam o relevo do Perfil da serra do Mar, com nível do mar há 11 mil anos e Perfil da serra do Mar, com

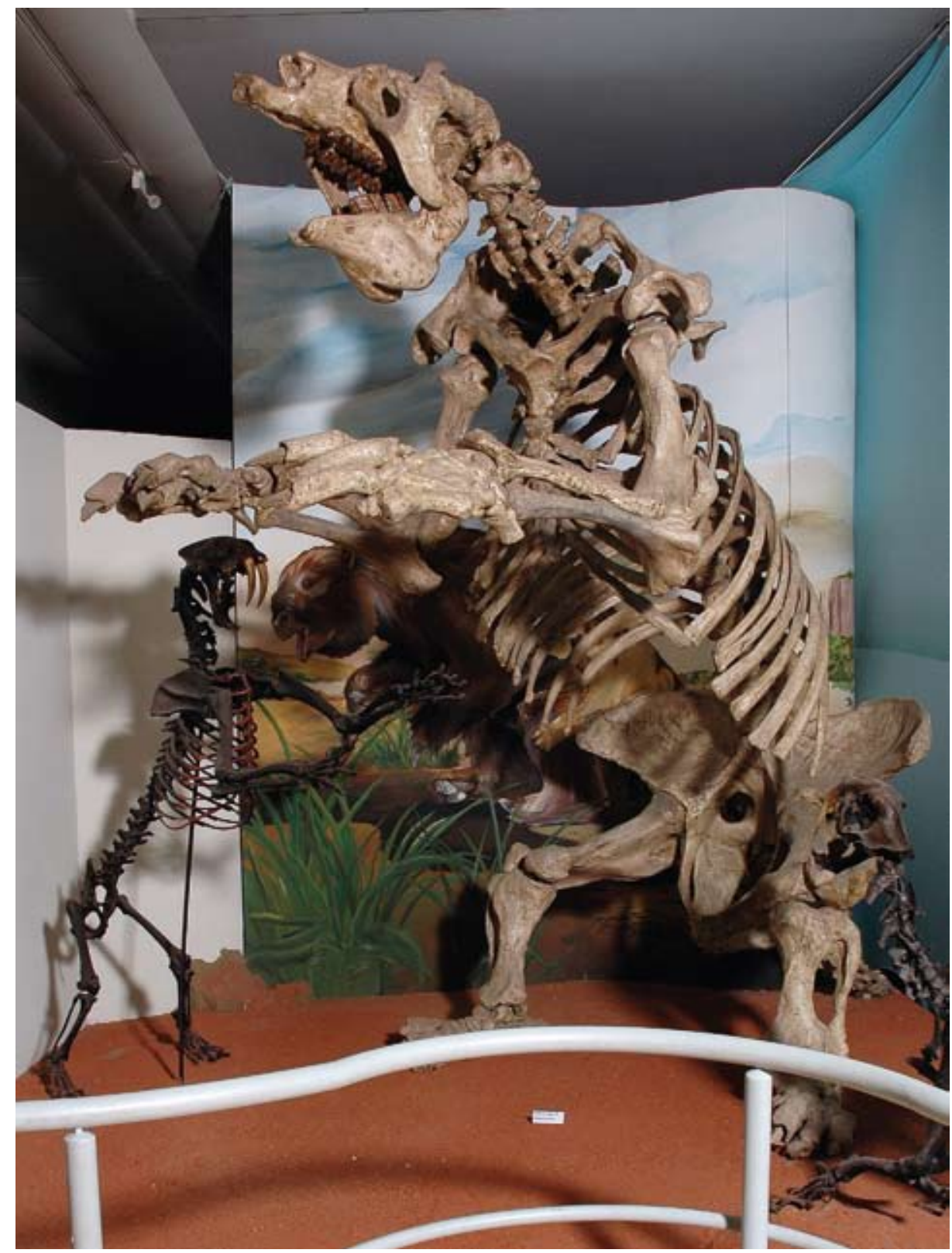

Figura 9 - Exemplo de réplicas produzidas a partir de moldes originais: preguiça-gigante e tigres-dente-de-sabre, da montagem Megafauna, Museu de Zoologia da USP, São Paulo. Fotografia de José Rosael, 2008. 
nível do mar atual, e que permitem evidenciar, em diminutas dimensões, tais diferenças de situação (Figura 12).

Vale ressaltar aqui que os modelos são instrumentos essenciais no desenvolvimento da ciência e, em função disto, conquistaram um lugar central na educação formal, embora nela nem sempre se discuta o processo de construção
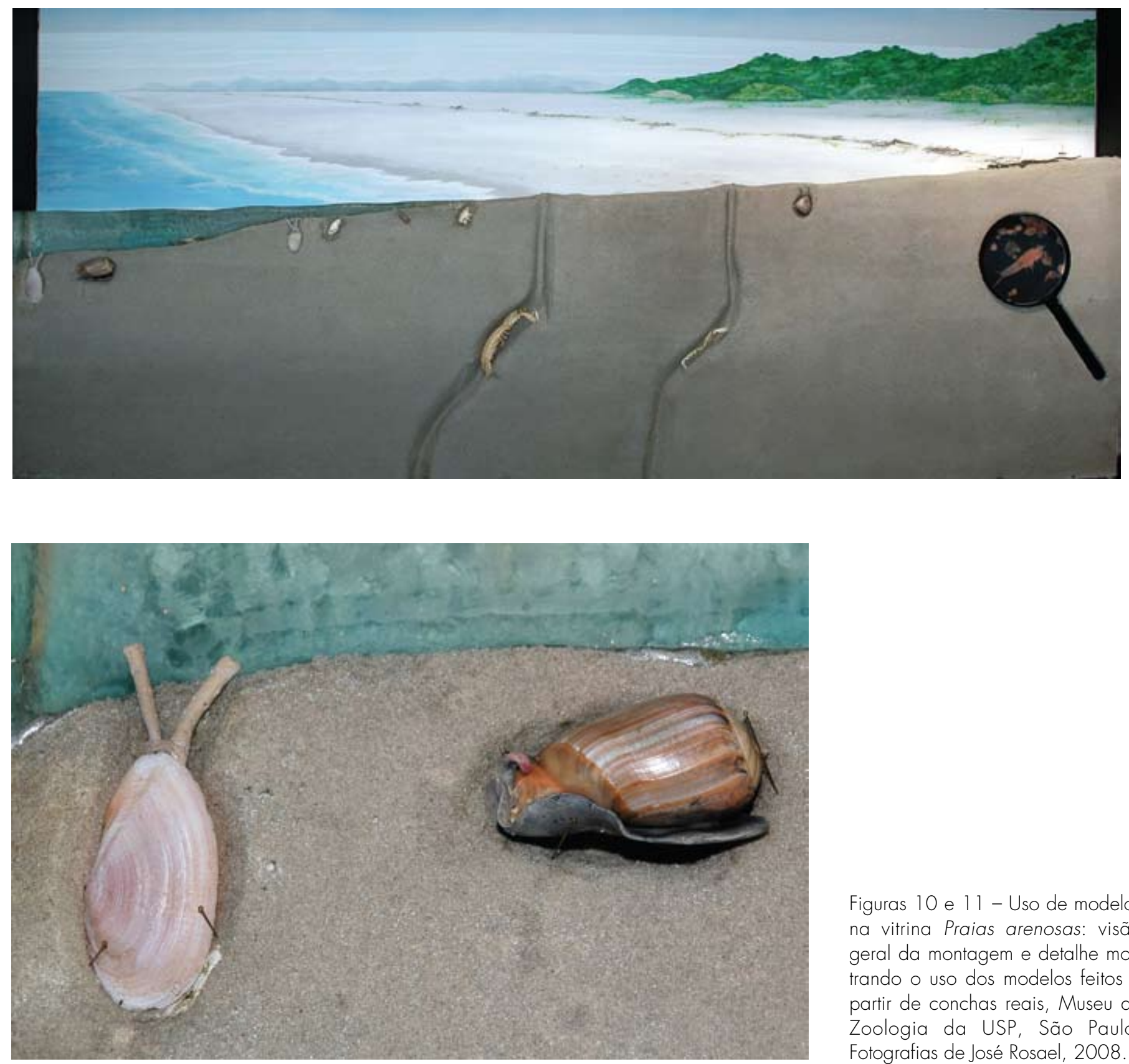

Figuras 10 e 11 - Uso de modelos na vitrina Praias arenosas: visão geral da montagem e detalhe mostrando o uso dos modelos feitos a partir de conchas reais, Museu de Zoologia da USP, São Paulo. Fotografias de José Rosael, 2008. 


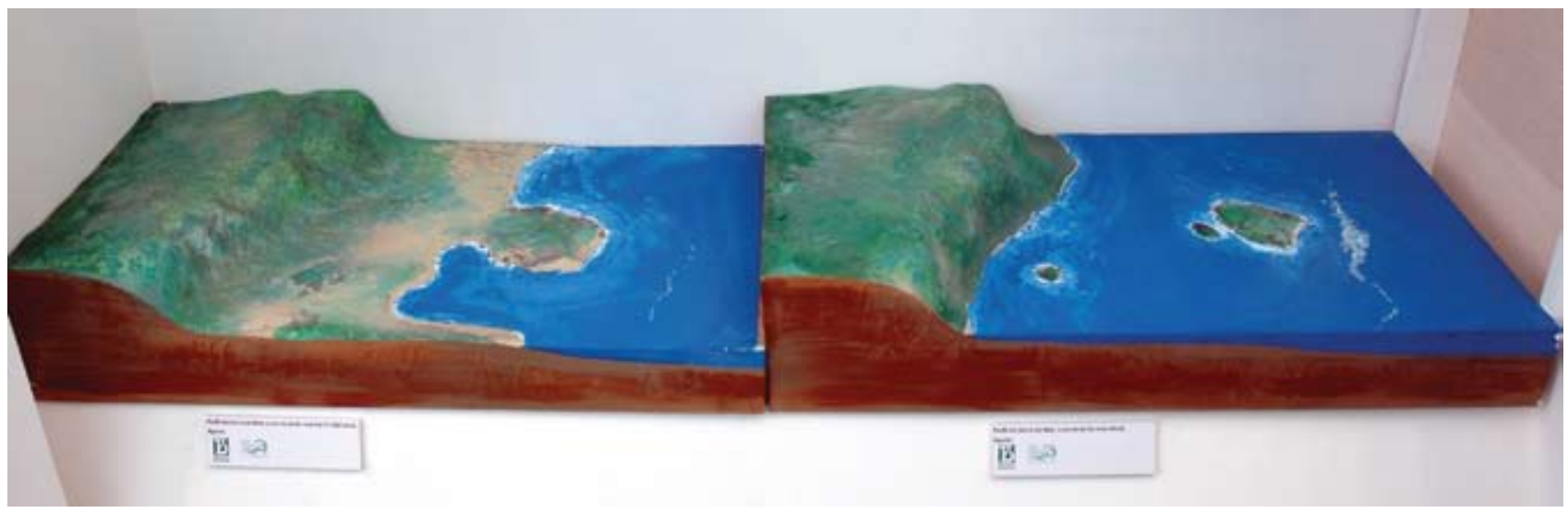

Figura 12 - Perfil da serra do Mar, com nível do mar há 11 mil anos e Perfil da serra do Mar, com nível do mar atual. Exemplo de modelo utilizado para representar em pequenas dimensões algo que, do contrário, não poderia ser exposto em função do tamanho e da escala de tempo. Fotografias de José Rosael, 2008.

90. Cf. Governo do Estado de São Paulo (1987, p. 32).

91. Cf. Clara Correia d'Alambert \& Marina Garrido Monteiro (1990, p. 77).

92. Cf. Roger S. Miles (1988, p. 85).

93. Cf. Mikel Asensio \& Elena Pol (1996, p. 11).

94. Cf. Roger S. Miles (1988 p. 85).

95. Ver Mikel Asensio \& Elena Pol (1996). da ciência. Neste sentido, a exposição deveria sempre deixar claro que, embora os modelos guardem uma relação com a realidade, eles não são a realidade.

- Manual de orientação museológica e museográfica, organizado pelo Governo do Estado de São Paulo sugere que, para conseguir uma exposição didática e que se aproxime da realidade do ambiente em que vive o animal, utilize-se a técnica dos dioramas, podendo ser acrescida da gravação de vocalizações ${ }^{90}$. Alambert e Monteiro também sugerem o uso de dioramas na apresentação de animais taxidermizados ${ }^{91}$.

Os dioramas eram originalmente compostos apenas por imagens. Mais tarde, adicionaram-se os objetos, a fim de aumentar a sensação de realismo ${ }^{92}$. Asensio e Pol expõem que os dioramas permitem representação, ambientação e contextualização realística de peças originais a serem expostas ${ }^{93}$. Complementando, Miles acredita que os dioramas têm como vantagem permitir a apresentação de objetos tridimensionais em um dado contexto, combinados em eventos que não ocorreriam simultaneamente no mundo real ${ }^{94}$. São exemplos de dioramas as reconstituições de biomas brasileiros exibidas no último módulo da exposição como Cerrado e A Floresta Amazônica (Figuras 13, 14 e 15). No último, representou-se, simultaneamente, um grupo de pequenos primatas de espécies diferentes, uma onça e um gavião pega-macaco predando um macacoprego, por exemplo.

Em pesquisa comparativa de diferentes displays de uma exposição do Milwaukee Public Museum, Asensio e Pol buscam definir se os dioramas apresentariam vantagens comunicativas com relação aos outros displays ${ }^{95}$. A pesquisa que utilizou a observação de público como ferramenta, apontou que os dioramas parecem ser o tipo de display com maior poder de atração e de retenção da atenção e o que provoca os maiores níveis de interação e envolvimento intelectual. $\bigcirc$ trabalho também indicou que, no caso dos dioramas, tamanho é uma variável importante, em geral os maiores sendo os mais atrativos. 


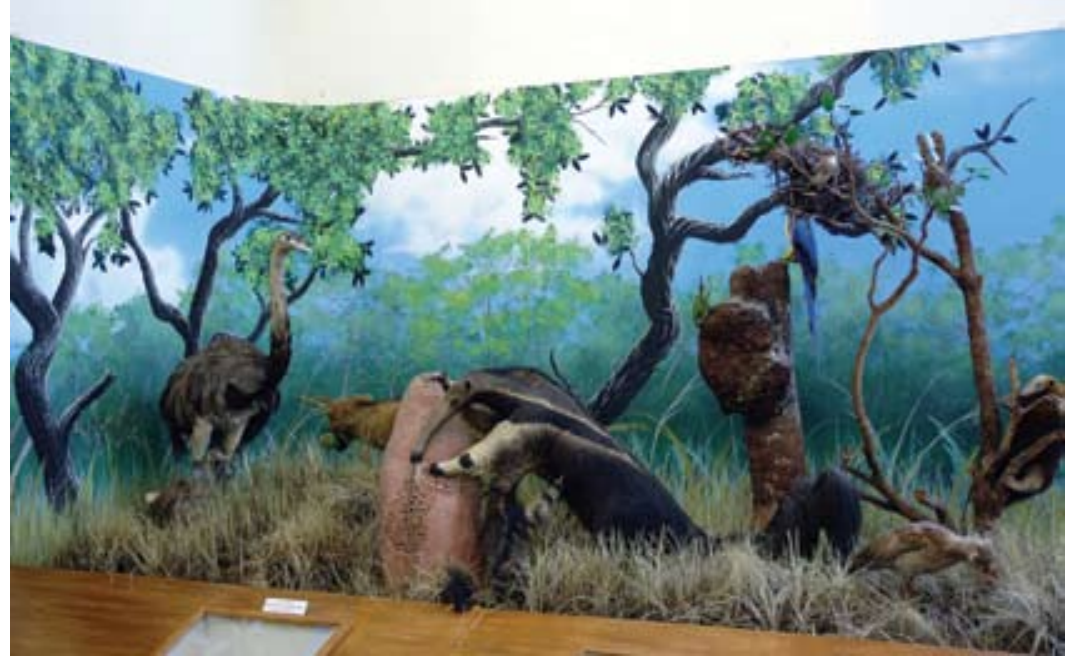

Figura 13: Diorama Cerrado, Museu de Zoologia da USP, São Paulo. Fotografia de José Rosael, 2008.
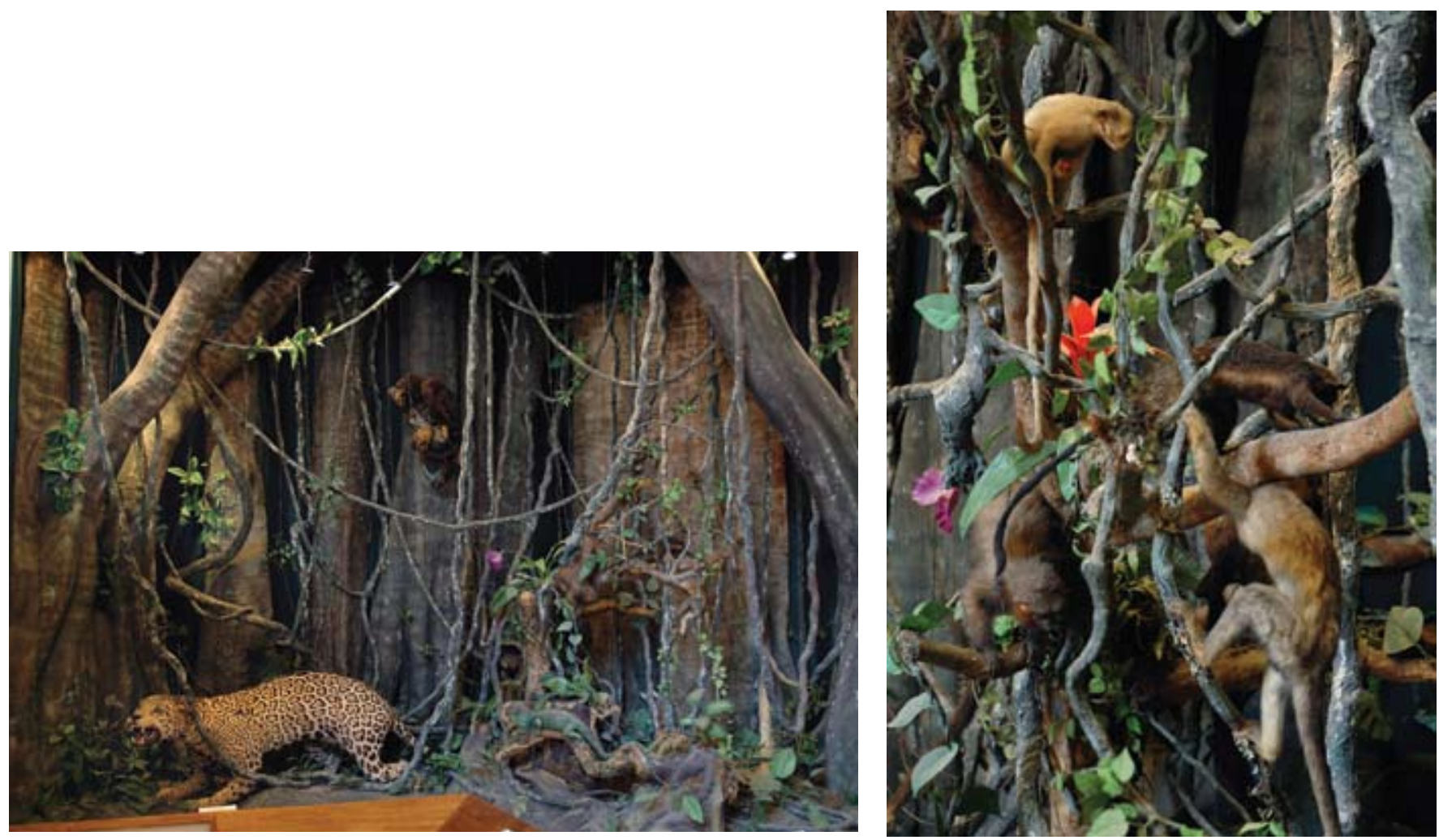

Figuras 14 e 15: Diorama A Floresta Amazônica: visão geral da montagem e detalhe mostrando grupo de pequenos primatas de espécies diferentes reunidas na montagem, Museu de Zoologia da USP, São Paulo. Fotografia de José Rosael, 2008. 
96. Cf. Robert Hodge \& Wilfred D'Souza (1999, p. 58).

97. Cf. Roger S. Miles (1988, p. 89)

98. Cf. Robert Hodge \& Wilfred D'Souza (1999, p. 59).

99. Cf. Roger S. Miles (1988, p. 80)

100. Cf. Robert Hodge \& Wilfred D'Souza (1999, p. 58).
No mais, os resultados mantiveram-se idênticos, independentemente da faixa etária e gênero dos visitantes, bem como do fato de estes circularem sozinhos ou em pequenos grupos, acompanhados ou não de crianças.

Dioramas, modelos ou réplicas teriam vantagem similar aos objetos, com relação às fotografias, uma vez que sua tridimensionalidade permite noções espaciais ${ }^{90}$. A vantagem com relação aos objetos reais é que, aqui, a escala pode ser controlada, e a fragilidade, contornada.

Já as fotografias são vistas por Miles como a forma mais realista de representação, uma vez que "uma foto não mente", isto é, outras formas de representação científica como diagramas e desenhos, têm seu conteúdo informativo controlado pelo designer ${ }^{97}$. Hodge e D'Souza acrescentam, ainda, que fotografias, assim como artefatos, não comunicam, por si só, conceitos abstratos $^{98}$. As fotografias, no entanto, podem ser uma alternativa para representação de estruturas extremamente diminutas, como organismos intersticiais mostrados em fotografia da vitrina Praias arenosas (Figura 16); ou animais vivos e em seu ambiente, como no painel Moluscos (Figura 17). Os diagramas e desenhos, por mostrar apenas o que neles está codificado, podem apresentar elementos e relações que não são simultâneas no tempo e no espaço, o que permite a comunicação de conceitos abstratos, como o processo de Formação dos fósseis (Figura 18).

Miles lembra, ainda, que alguns displays são certamente mais atrativos que outros, isto é, objetos reais e displays participativos são mais atraentes que pôsteres com gráficos estáticos ${ }^{99}$. No geral, um display que é associado a uma opção de entretenimento é mais atraente do aquele que remete à educação formal.

Ainda com relação às formas de montagem de exposição, vale ressaltar, como o fazem Hodge e D'Souza, que, nas vitrinas, a barreira do vidro restringe em muito o potencial comunicativo dos objetos, uma vez que a comunicação passa a dar-se apenas por meio de um dos sentidos, a visão, e limitada a certa distância, ângulo de visão etc ${ }^{100}$.

Níveis de interatividade

Ao analisar os visitantes espontâneos dos museus, Screven indica que a maioria deles tem uma forte orientação visual/sensorial, ou seja, seu interesse se volta à exploração visual do ambiente museal, principalmente dos objetos e outros elementos de encenação. $\bigcirc$ autor define ainda uma escala onde os elementos que despertariam prioritariamente $\mathrm{O}$ interesse seriam os organismos vivos, os objetos que se movem ou que convidam o visitante a utilizar seus sentidos (tocar, manipular), e as novidades (elementos recentes, únicos ou que formam conjuntos inusitados). Os elementos não prioritários compreenderiam os painéis, murais passivos bidimensionais, e os textos tradicionais ${ }^{101}$. 


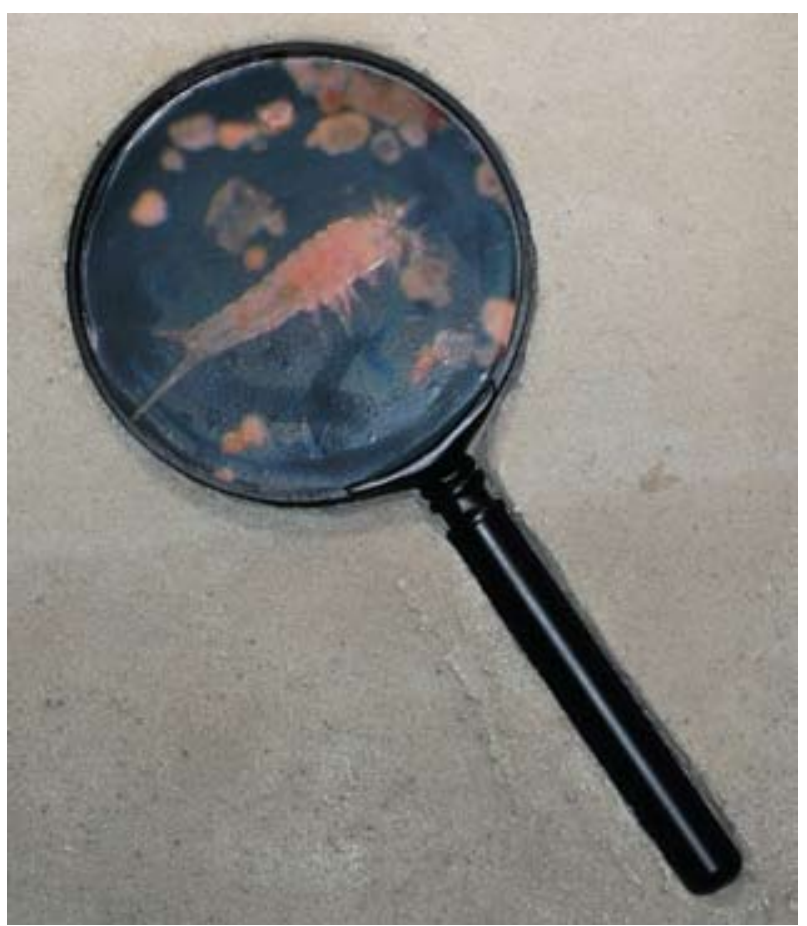

Figuras 16 e 17 - Detalhe da montagem Praias arenosas, mostrando organismo intersticial, e painel Moluscos, exemplos de uso de fotografias para expor organismos de dimensões microscópicas e organismos vivos, Museu de Zoologia da USP, São Paulo. Fotografia de José Rosael, 2008.

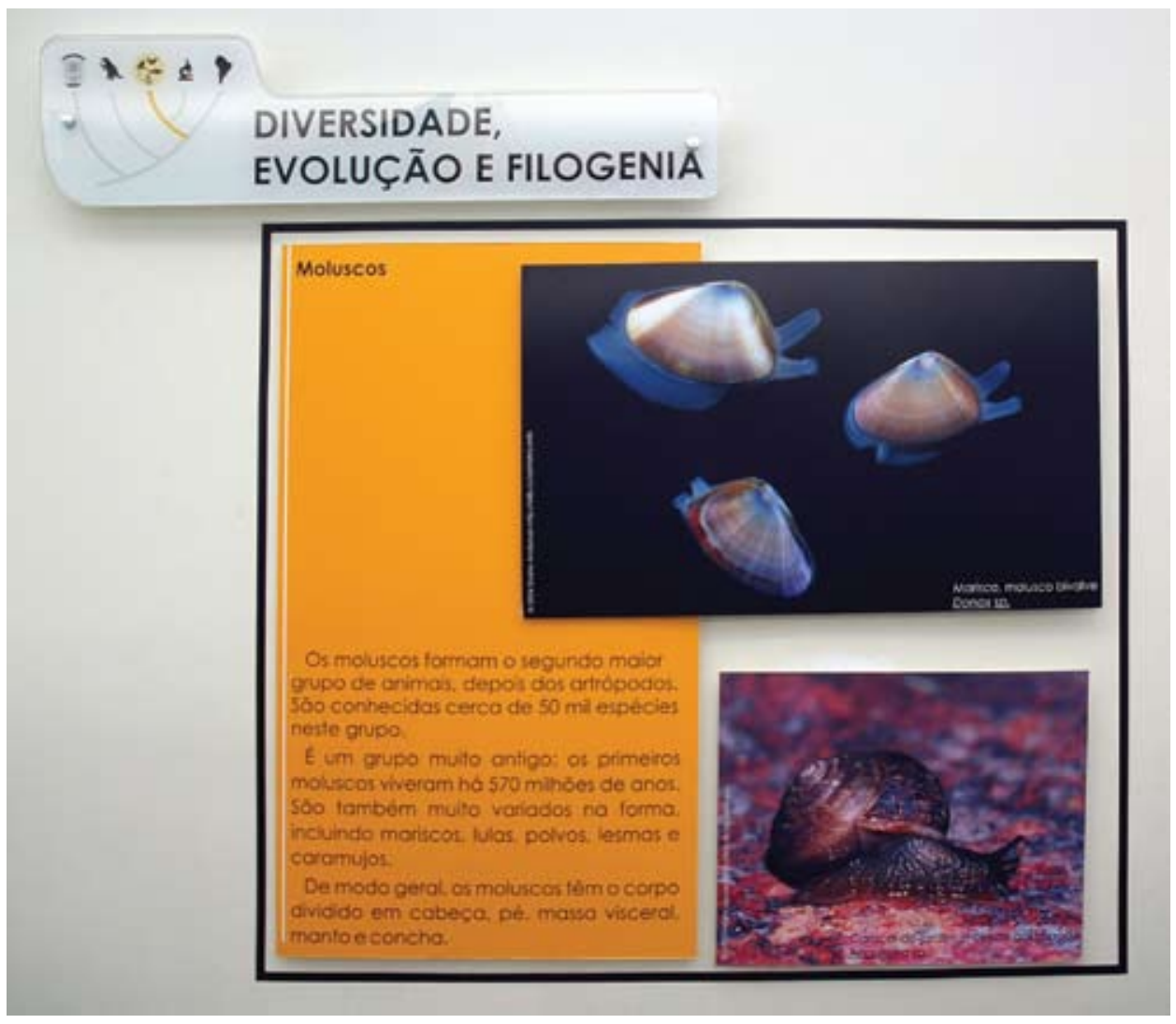

Annals of Museu Paulista. v. 16. n.2. July - Dec. 2008. 
101. Cf. Chan G. Screven (1993, p. 11).

102. Ver Edward P. Alexander (1979).

103. Ver Janette Griffin (1998); John K. Gilbert \& Susan Stocklmayer (2001).

104. Cf. Dominique Colinvaux (2005, p. 81).

\section{Formaçāo de fósseis}

A formação de um fóssil pode acontecer quando um organismo morto é coberto por lama ou lodo e não apodrece rapidamente.

Com o tempo, a cobertura endurecee os ossos do organismo morto, ou sua concha, são substituidos por minerais. É Um fenômeno raro e às vezes fica só a marca do animal ou planta Inarocha.
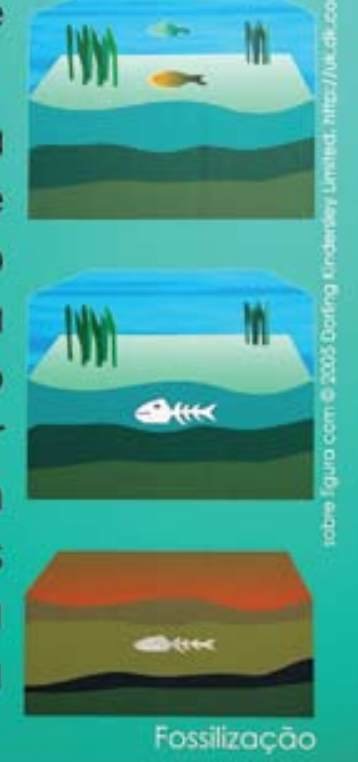

Figura 18 - Exemplo do uso de diagrama/desenho, para explicação de conceito, no painel Formação de fósseis, Museu de Zoologia da USP, São Paulo. Fotografia de José Rosael, 2008.

O trabalho de Alexander, embora anterior, já apontava favoravelmente a exploração das diferentes percepções sensoriais e não apenas da visão ${ }^{102}$. Isto porque estímulos sensoriais podem proporcionar reações emocionais, e estas, ao trabalharem em conjunto com o racional, levariam a uma melhor compreensão da exposição. Assim, a ampliação do leque de sentidos estimulados poderia ser um catalisador de todo o processo.

Em função disto, alguns autores se interessam pela interatividade enquanto opção para o aprendizado ${ }^{103}$. Na presente reflexão, no entanto, não será discutida a relação da interatividade com o aprendizado do visitante. Aqui, a interatividade é considerada como uma das ferramentas de comunicação a que o idealizador da exposição pode recorrer para atingir seus objetivos, quaisquer que sejam.

A interatividade, segundo Colinvaux, parece estar no cerne da experiência museal ${ }^{104}$. Assim, as exposições, para Wagensberg, devem estimular os visitantes, estes estímulos se dando através da interatividade ${ }^{105}$. Miles, por sua vez, também afirma que a melhor forma de se conhecer algo é via interação, 
uma vez que esta faz com que as "coisas" se tornem verdadeiramente "reais" para aquele que as vive ${ }^{106}$.

No entanto, se a possibilidade de interagir pode suscitar a atenção do visitante, Screven adverte que, a menos que seja cuidadosamente integrada aos objetivos educativos, ela pode também distrair o visitante, fazendo-o inclusive perder a linha de raciocínio da exposição. $O$ autor chama a atenção para o fato de que, muitas vezes, o visitante pode explorar um elemento museográfico interativo sem, no entanto, refletir sobre o que está fazendo. Cita, por exemplo, que divertimento e participação, muitas vezes observados nas exposições de vulgarização científica, não significam que a educação científica esteja realmente acontecendo, podendo ser simples reflexo da excitação provocada pela liberdade de exploração, e defende que uma boa opção seria subordinar elementos divertidos à atenção e ao aprendizado, uma vez que, para ele, no museu, a diversão deve ser um meio para se atingir um objetivo, o aprendizado, por exemplo, e não o objetivo em si ${ }^{107}$.

Neste sentido, Mclean explica que, no contexto dos museus, o termo "interativo" tem sido utilizado como sinônimo de "participativo" ou "manipulativo" (hands-on), o que pode gerar confusões ${ }^{108}$. A autora lembra que nem toda manipulação é uma interação, e que a interação acontece quando o visitante age sobre a exposição e esta faz algo que age sobre o visitante. Assim, o termo "participativo" define a relação do visitante com a exposição, enquanto o termo "interativo" enfatiza a capacidade da exposição de responder a estímulos do $v_{\text {visitante }}^{109}$. Tal definição de exposição interativa já era adotada por Miles ${ }^{110}$. É também possível falar de dispositivos com dois tipos de respostas diferentes: aqueles que sempre responderão da mesma forma à atuação do visitante, e aqueles que trazem ao visitante uma infinidade de opções de manipulações e conseqüentes respostas.

Asensio e Pol ainda acrescentam que, a seu ver, a interatividade deveria ter uma base cognitiva, centrada na análise do processo mental e no produto resultante. Os autores citam como exemplo que a mente de um especialista, frente à obra de Frei Angélico, está desenvolvendo uma interatividade de alto nível, embora seu corpo permaneça estático ${ }^{11}$ '. Já Colinvaux, ao referir-se a interatividade, cita que esta, nos museus, pode ocorrer entre sujeitos, entre sujeitos e objetos, e também entre sujeitos e contextos, onde o museu é contexto para a ação do sujeito ${ }^{12}$.

Focando na interação entre sujeitos e objetos, Wagensberg define três níveis de interatividade: hands on (manual), minds on (mental) e heart on (emoção cultural). $\bigcirc$ primeiro destes níveis seria a interatividade manual ("hands on'l em que o visitante manipula modelos, objetos ou montagens que the permitam entender o funcionamento e o desenrolar de processos e fenômenos. É a idéia de que o visitante experimenta o método científico, o visitante "é" o cientista ${ }^{13}$. Esta idéia de experimentação parece estar, segundo Colinvaux, na origem de vários museus interativos de ciências ${ }^{114}$.
105. Cf. Jorge Wagensberg (2000, p. 16).

106. Cf. Roger S. Miles (1988, p. 95).

107. Cf. Chan G. Screven (1993, p. 12).

108. Cf. Kathleen McLean (1993, p. 92).

109. Idem, p. 93.

110. Cf. Roger S. Miles (1988, p. 96).

111. Cf. Mikel Asensio \& Elena Pol (1996, p. 18).

112. Cf. Dominique Colinvaux $(2005$, p. 81).

113. Cf. Jorge Wagensberg (2000, p. 16). 
114. Cf. Dominique Colinvaux (2005, p. 82).

115. Cf. Kathleen Mclean (1993, p. 93).

116. Idem, p. 94

117. Cf. Roland Arpin (1989, p. 67).

118. Cf. Chan G. Screven (1993, p. 19).

119. Cf. Jorge Wagensberg (2000, p. 17).

120. Ibidem
As exposições participativas ou interativas estão presentes nos museus há muito tempo ${ }^{115}$. Já no século XIX surgem exposições que estimulam a manipulação pelo visitante. Esta manipulação pode se dar diretamente (hands-on) ou por meio de mecanismos acionados pelo visitante por um simples toque (push button). Este tipo de exposição geralmente é associado ao aumento do número de crianças nos centros de ciências nos anos 1970-1980, o que mostra como o conceito de participação do público foi sendo bem lentamente incorporado 116

No entanto, Arpin adverte quanto ao uso tentador do que ele chama de uma gadget museology ${ }^{17}$, ou seja, exposições que utilizam um excesso de dispositivos mecânicos ou tecnológicos e assim se tornam verdadeiro mostruário de efeitos especiais. A seu ver, todas essas ferramentas ou todas essas formas de apresentação favorecem a contextualização, cativam o visitante e criam uma atmosfera agradável, o que, sem dúvida, faz parte da mensagem do museu, mas que não poderiam ser "a mensagem".

Screven aponta, ainda, que a interação não ocorre apenas com o uso de aparelhos e dispositivos manipuláveis ${ }^{118}$. A interação objetivando o encorajamento da observação e da reflexão pode se dar com o uso de dispositivos simples, como questões ou desafios que estimulam o visitante a buscar pistas e respostas; ou, ainda, os painéis-perguntas, com respostas escondidas.

Neste sentido, Wagensberg define outro nível de interatividade presente nas exposições - a interatividade mental ("minds on") -, que levaria a uma compreensão científica: distinguir o essencial do acessório, ver o que há de comum entre o que é aparentemente distinto, estabelecer relações entre o que se vê no museu e no cotidiano 19

Neste tipo de interatividade, poderíamos facilmente encaixar exposições que lidam com questões controversas, estimulando o diálogo entre diferentes perspectivas, desafiando o visitante do ponto de vista cognitivo e emocional, e levando-o a assumir uma postura crítica.

O terceiro tipo estabelecido por Wagensberg é a interatividade cultural (heart on) explicando que, embora a ciência seja universal, a realidade na qual ela se desenvolve não o él20. Assim, para promover a interatividade cultural, uma exposição deve tentar priorizar as identidades presentes no entorno do museu, promovendo a identificação, com o acervo, do visitante da comunidade local; e um despertar para uma nova cultura, quando o visitante é de outras localidades. É o tipo de interatividade que ocorre quando o Museu de Zoologia opta, por exemplo, por compor suas exposições a partir de organismos neotropicais, que despertam no visitante brasileiro uma identidade, enquanto proporcionam ao estrangeiro um contato com ambientes que não o de sua naturalidade.

A expressão "enfoque glocal", que tem sido bastante utilizada nos últimos anos, poderia talvez retratar este tipo de interatividade, uma vez que define a promoção de uma abordagem de temas globais a partir de temáticas locais e vice-versa. Isto significa não só o estabelecimento de conexões familiares (do local para o global) e a aproximação de temáticas ditas distantes (do global para o locall, mas a valorização da identidade das comunidades locais, o 
reforço dos laços com esta comunidade, e até o reforço da identidade do museu dentro dessa comunidade.

A exposição, segundo Girault e Guichard, pode ainda, por sua apresentação cenográfica das coleções, criar um impacto emocional que estimula o interesse do visitante e favorece a memorização ${ }^{121}$. Cabe perguntar se este estímulo emocional ou afetivo poderia ser considerado como o nível heart on de interatividade, descrito por Wagensberg ${ }^{122}$.

Nem sempre, no entanto, os três níveis de interatividade definidos por Wagensberg (hands on, minds on e heart onl podem ser encontrados juntos em uma mesma exposição. O autor comenta que o ideal é a presença simultânea dos três, mas define um gradiente de importância em que a interatividade manual aparece como conveniente; a cultural, como recomendável; e a mental, como imprescindível ${ }^{123}$. Um grande exemplo da presença simultânea de diversos níveis de interatividade pode ser observado, no Museu de Zoologia, no módulo Fauna neotropical e ambiente marinho. Aí são apresentadas reconstituições de grandes biomas brasileiros, dispostas em torno de um mapa da região neotropical, colocado no solo (Figura 19). Os visitantes podem, assim, buscar a região em que vivem, em alguns casos até a cidade, ou então lugares que visitaram nas férias, ou seja, há uma manipulação de instrumentos de pesquisa científica lum
121. Ver Yves Girault e Françoise Guichard (2000)

122. Cf. Jorge Wagensberg (2000, p. 17).

123. Idem, p. 16.

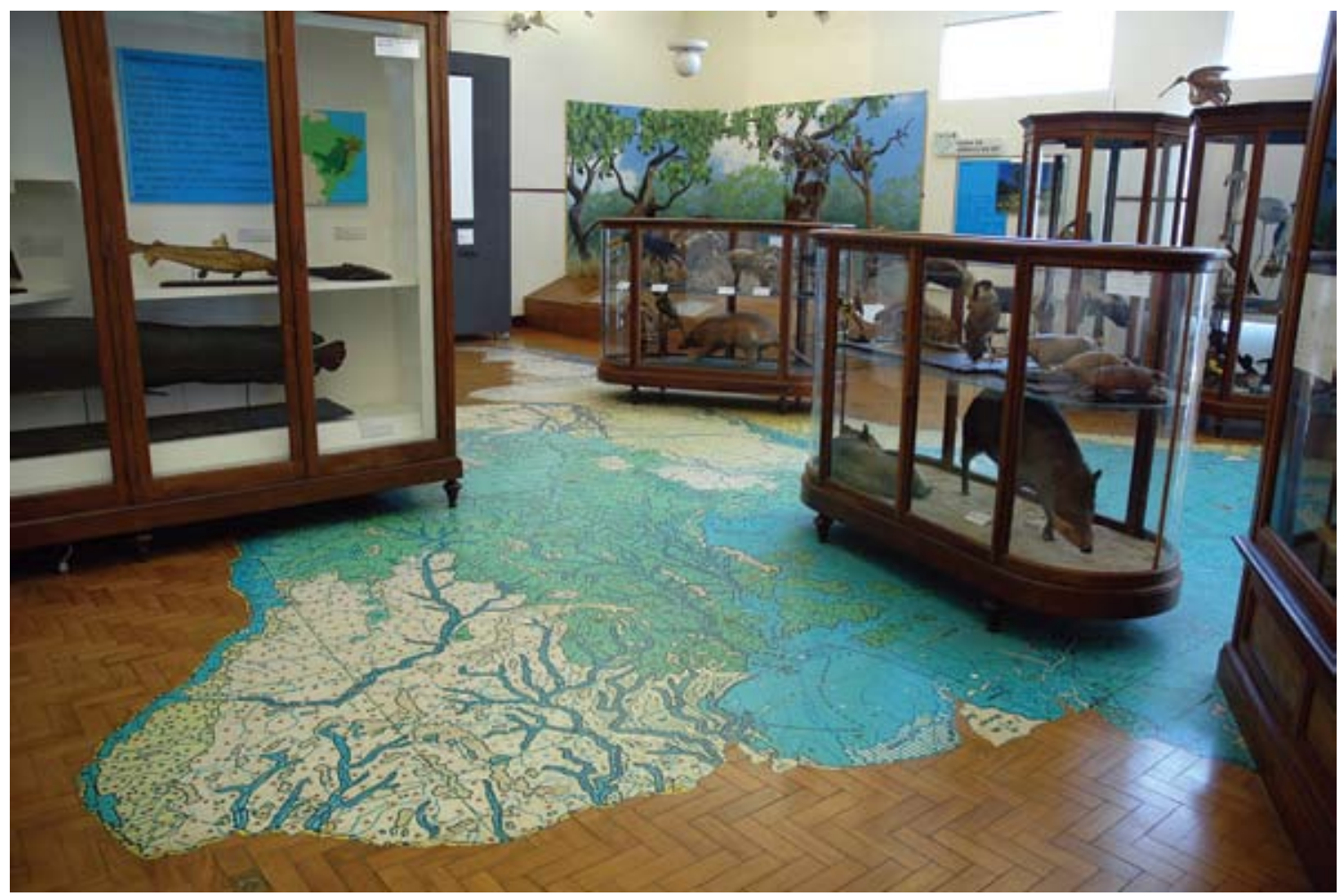

Figura 19 - Mapa da região neotropical colocado no chão, exemplificando montagem com presença simultânea de diversos níveis de interatividade, que pode ser observada no módulo Fauna neotropical e ambiente marinho, Museu de Zoologia da USP, São Paulo. Fotografia de José Rosael, 2008.

Annals of Museu Paulista. v. 16. n.2. July - Dec. 2008. 
124. O trabalho de Adriana Mortara Almeida (2004) única pesquisa de público desenvolvida no Museu de Zoologia já publicada, buscou traçar o perfil dos visitantes e não-visitantes, bem como suas motivações para a visita.

125. Cf. Denis Samson (1992, p. 63).

126. Idem, p. 68.

127. Cf. Roland Arpin (1989, p. 61). O conceito de aprendizagem em museus vem sendo, atualmente, questionado. Parece-nos que este não é sequer o ponto central, uma vez que entendemos a sensibilização para o universo científico - e não a apreensão de conceitos científicos - como a contribuição mais importante que possa ser oferecida pelos museus de ciências. mapa), há um estímulo para o estabelecimento de relação entre o que se vê no Museu e o cotidiano do visitante, e há uma identificação do que é visto no Museu com o ambiente do visitante.

Conclusões e últimas considerações

As reflexões levadas a efeito permitem o estabelecimento de algumas categorias para análise e discussão de práticas expográficas em museus de ciências, algumas delas podendo ser estendidas a museus de outras áreas de conhecimento, desde que adaptadas ao contexto. Outras categorias poderiam ser estabelecidas para a análise dos mesmos aspectos. Outros aspectos e recortes, como circulação ou paradigma educacional, poderiam ser analisados. A exposição, com suas características espaciais, temporais e comunicacionais específicas, é uma mídia complexa.

Neste sentido, esta reflexão, não pretendeu fornecer referências lou uma receita) para a exposição ideal, mas teve por objetivo apontar alguns tópicos de suma importância quando da concepção ou avaliação de exposições enquanto instrumento de comunicação do museu com o seu público. No Museu de Zoologia aqui citado, a eficácia comunicativa das estratégias ora discutidas ainda não foi objeto de estudo de público ${ }^{124}$.

Aqui, não foram discutidos os textos expositivos, talvez por que, como comenta Samson, o visitante faça uma seleção na informação disponível e esta seleção dependa de estímulos recebidos ao longo de uma seqüência de observação ${ }^{125}$. Esta seqüência apresentaria três etapas principais e decisivas: primeiro, o visitante observa a iconografia disponível; em seguida, dirige seu olhar para títulos e subtítulos, chegando então às legendas (o que marca um retorno à iconografia) e aos textos. Deixa claro, portanto, que o retorno da atenção à iconografia - e aqui, poderíamos acrescentar, igualmente aos objetos - derruba a perspectiva tradicional de uma primazia dos textos sobre os outros elementos museográficos. O que não quer dizer, como também Samson já explicitava, que o texto possa ser marginalizado, mas que, ao contrário, ele deve estar integrado ao restante da exposição ${ }^{126}$.

O texto, em oposição ao objeto, parece ser, no entanto, um elemento comum a diversas formas de mídia de divulgação, merecendo, portanto, estudo diferenciado.

Ao pensar nas diferenças, Arpin (1989, p. 61) já apontava para a necessidade de se refletir, a fim de definir por que o museu pode ser um meio mais apropriado que um filme, uma aula, um livro ou um programa de televisão, para atingir objetivos de aprendizagem de conhecimentos científicos ou simplesmente favorecer uma sensibilização para com o universo científico ${ }^{127}$.

Talvez os níveis de interatividade descritos por Wagensberg ${ }^{128}$ respondam tal questão. A interatividade é tida por muitos como suporte para aprendizagem, com o objetivo de complementar a educação formal; mas ela 
deve ser considerada também uma importante ferramenta de comunicação, podendo, inclusive, promover entretenimento e tornar-se o elemento expositivo popularizador de uma instituição museológica. É, então, importante atentar para o fato de que a maioria dos museus não desenvolve todos os diferentes níveis de interatividade, já citados, descritos por Wagensberg; e, para aqueles níveis que são trabalhados pelas exposições, parece muitas vezes ser tímida a exploração de seu potencial.

Neste sentido, é importante lembrar que o último censo realizado pelo Instituto Brasileiro de Geografia e Estatística ${ }^{129}$ apontou que 14,5\% da população brasileira apresentam alguma necessidade especial permanente e, destes, cerca de $70 \%$ apresentam algum grau de deficiência visual permanente. Além disso, é evidente que um público heterogêneo, como é o caso na maioria dos museus, necessariamente deve redundar em heterogeneidade nas formas de comunicação. Assim, um leque de opções, mesmo que todas referentes ao mesmo tema, que incluam interatividades, manipulações, contemplações, leituras, entre outras, parece ser a melhor estratégia para promover acessibilidade e eficácia comunicacional de uma exposição.

Uma pesquisa de avaliação das mudanças realizadas com intuito de melhorar a acessibilidade em uma sala de exposições do Boston Museum of Science foi apresentada por Davidson, Heald e Hein. As modificações envolviam, essencialmente, o acréscimo de pequenos textos, modelos, elementos manipuláveis e estações multisensoriais junto a displays já existentes. A pesquisa mostrou que o tempo despendido pelo público nesta sala aumentou (maior poder de atração, inclusive de displays antigos), e a forma de interação visitante-exposição tornouse mais ativa. Por outro lado, a sala tornou-se mais barulhenta, o que afugenta uma parcela do público que parecia apreciar o silêncio monacal ali antes existente $^{130}$. A pesquisa sugere que os museus podem preservar suas montagens tradicionais, a elas acrescentando elementos complementares, como as estações multisensoriais. Ainda segundo os autores, a maior conclusão do trabalho é mostrar que estas alterações, feitas a priori para atender um público portador de necessidades especiais, resultaram em um aumento no tempo despendido na sala e, conseqüentemente, no seu potencial de comunicação, para todos os públicos ${ }^{131}$.

É claro, como já ressaltado por McLean, que nem toda idéia ou conceito pode ser bem veiculado através da interatividade ${ }^{132}$ e que, para a preparação deste tipo de exposição, muitos fatores devem ser levados em consideração, dentre eles o design técnico e a engenharia, que nem sempre fazem parte da rotina da instituição. Pode se levantar, ainda, que desenho e desenvolvimento de projeto de engenharia para exposições podem demandar um investimento financeiro importante. No entanto, existem muitas possibilidades para exposições participativas e interativas e, modificações simples, como as descritas pelos já citados Davidson, Heald e Hein, podem trazer resultados inesperados e garantir que o museu seja realmente acessível a todos.
128. Cf. Jorge Wagensberg (2000, p. 16).

129. Ver o Censo do IBGE (2000).

130. Cf.Betty Davidson Candance L. Heald \& George E. Hein (1999, p. 235).

131. Idem, p. 237

132. Cf. Kathleen McLean (1993, p. 94) 


\section{REFERÊNCIAS}

ALAMBERT, Clara Correia d'; MONTEIRO, Marina Garrido. Exposição: materiais e técnicas de montagem. São Paulo: Secretaria de Estado da Cultural, 1990. 86 p.

ALEXANDER, Edward P. Museums in motion: An Introduction to the History and Functions of Museums. Tennessee: American Association for State and Local History, 1979. 308 p.

ALMEIDA, Adriana Mortara. Os visitantes do Museu Paulista: um estudo comparativo com os visitantes da Pinacoteca do estado e do Museu de Zoologia. Anais do Museu Paulista: História e Cultura Material, São Paulo, Nova série, v. 12, p. 269-306, 2004.

ALVES, Ana Maria de Alencar. O Ipiranga apropriado: ciência, política e poder; o Museu Paulista, 1893-1922. São Paulo: Humanitas/FFLCH-USP, 2001. 213 p.

ARPIN, Roland. Pour les années quatre-vingt-dix, un marriage à trois; museologie, communication et pédagogie. In: SCHIELE, Bernard (Coord.). Faire voir, faire savoir: la museologie scientifique au présent. Canada: Musée des Civilisations, 1989. p. 61-71.

ASENSIO, Mikel; POL, Elena. ¿Sieguen siendo los dioramas uma alternativa efectiva de montaje? Revista de Museologia, Madrid, n. 8, p. 11-20, Julio de 1996.

BENNETT, Jim. Can science museum take history seriously? In: MACDONALD, Sharon (Ed.). The politics of Displays: museums, science, culture. Oxon and New York: Routledge, 2001. p. 173182.

BENNETT, Tony. Speaking to the eyes: Museums, legitimity and the social order. In: MACDONALD, Sharon (Ed.). The politics of Displays: museums, science, culture. Oxon and New York: Routledge, 2001, p. 25-35.

CARVAlhO, A. M. Galopim de. Os museus e o ensino das ciências. Revista de Educação, Lisboa, v. 3, n. 1, p. 61-66, junho de 1993.

COLINVAUX, Dominique. Museus de ciências e psicologia: interatividade, experimentação e contexto. História, Ciências, Saúde: Manguinbos, Rio de Janeiro, v. 12, suplemento, p. 79-91, 2005.

CURY, Marília Xavier. Exposição: concepção, montagem e avaliação. São Paulo: Annablume, 2005. 162p.

Comunicação e pesquisa de recepção: uma perspectiva teórico-metodológica para os museus. História, Ciências, Saúde: Manguinbos, Rio de Janeiro, v. 12, suplemento, p. 365-380, 2005.

DAVALLON, Jean. Avant-propos. In: (Org.). Claquemurer, pour ainsi dire, tout l'univers. La mise en exposition. Paris: Éditions du Centre Georges-Pompidou, 1986. p. 7-16.

DAVALlON, Jean. Peut-on parler d'une "langue" de l'exposition scientifique? In: SCHIELE, Bernard (Coord.). Faire voir, faire savoir: la museologie scientifique au présent. Canada: Musée des Civilisations, 1989. p. 47-59. 
DAVIDSON, Betty; HEALD, Candance Lee; HEIN, George E. Increased exhibit accessibility through multisensory interaction. In: HOOPER-GREENHILL, Eilean (Ed.). The educational role of the museum, 2. ed. New York: Routledge, 1999. p. 223-238.

DEAN, David. Museum Exhibition: theory and practice. New York: Routledge, 2003. 177 p.

FALK, John H.; DIERKING, Lynn D. Learning from Museum: visitor experiences and the making of meaning. New York: Altamira, 2000.

Free-choice science education: how we learn science outside of school. New York: Teachers College-Columbia University, 2001.

FAYARD, P. La sorpresa de Copérnico: el conocimento gira alredor del público. Alambique: Didáctica de las Ciencias Experimentales, Barcelona, v. 6, n. 21, p. 9-16, jul. 1999.

GILBERT, John K.; STOCKLMAYER, Susan. The design of interactive exhibits to promote the making of meaning. Museum Management and Curatorship, London, v. 19, n. 1, p. 41-50, 2001.

GIRAULT, Yves; GUICHARD, Françoise. Spécificité de la didactique muséale en biologie. In: EIDELMAN, Jacqueline; VAN-PRAËT, Michel (Org.). La muséologie des sciences et ses publics. Regards croisés sur la Grande Galerie de l'Evolution du Muséum nacional d'histoire naturelle. Paris: Presses Universitaires de France, 2000. p. 63-74.

GRIFFIN, Janette. Learning science through practical experiences in museums. International Journal of Science Education, London, v. 20, n. 6, p. 655-663, 1998.

HODGE, Robert; D'SOUZA, Wilfred. The museum as communicator: a semiotic analysis of the Western Australian Museum Aboriginal Gallery, Perth. In: HOOPER-GREENHILL, Eilean (Ed.). The educational role of the museum. 2. ed. London: Routledge, 1999. p. 53-63.

HOOPER-GREENHILL, Eilean. Communication in theory and practice. In: (Ed.). The educational role of the museum. 2. ed. London: Routledge, 1999. p. 28-43.

IBGE (Instituto Brasileiro de Geografia e Estatística). Censo Demográfico 2000. Características gerais da população: resultados da amostra. Disponível em: <http://www.ibge.gov.br $>$. Acessos em 20 de junho de 2006 e 15 de julho de 2008.

LOPES, Maria Margaret; MURRIELLO, Sandra Elena. Ciências e educação em museus no final do século XIX. História, Ciências, Saúde: Manguinbos, Rio de Janeiro, v. 12, suplemento, p. 13-30, 2005.

MCLEAN, Kathleen. Planning for people in museum exhibitions. Washington, DC: Association of Science-Technology Centers, 1993. $196 \mathrm{p}$.

MCMANUS, Paulette M. Topics in Museums and Science Education. Studies in Science Education, n. 20 , p. $157-182,1992$.

MILES, Roger S. The design of educational exbibits. 2. ed. rev. London: Unwin Hyman, 1988. $198 \mathrm{p}$.

RIVIÈRE, Georges Henri. La museologie selon Georges Henri Rivière. Paris: Bordas, 1989. 402 p. + 72 p. não paginadas [entre as páginas 26-27; 88-89; 324-325; 370-371]. 
SAMSON, Denis. L'évaluation formative et la genèse du texte. Publics et Musées, Lyon, n. 1 (Textes et public dans les musées), p. 57-73, 1992.

SÃO PAULO (Governo do Estado). Manual de orientação museológica e museográfica. São Paulo: Imprensa Oficial do Estado-IMESP, 1987. 44 p.

SCREVEN, Chan G. Présentations didactiques pour visiteurs libres. ICOM Education, n. 12-13 (Recherche et education dans les musées), p. 10-20, 1993.

VALENTE, Maria Esther. A conquista do caráter público do museu. In: GOUVÊA, Guaracira; MARANDINO, Martha; LEAL, Maria Cristina (Org.). Educação e museu: a construção social do caráter educativo dos museus de ciência. Rio de Janeiro: Access, 2003. p. 21-45.

; CAZELLI, Sibele; ALVES, Fátima. Museu, ciência e educação: novos desafios. História, Ciências, Saúde: Manguinbos, Rio de Janeiro, v. 12, suplemento, p. 183-203, 2005.

VAN-PRAËT, Michel. Contradictions des musées d'histoire naturelle et evolution de leurs expositions. In: SCHIELE, Bernard (Coord.). Faire voir, faire savoir: la museologie scientifique au présent. Canada: Musée des Civilisations, 1989. p. 25-34.

VERGO, Peter. The Reticent Object. In: (Ed.). The new museology. London: Reaktion, 1989. p. 41-59.

WAGENSBERG, Jorge. Princípios fundamentales de la museología científica moderna. Alambique: Didáctica de las Ciencias Experimentales, Barcelona, n. 26, p.15-19, 2000.

The "total" museum, a tool for social change. História, Ciências, Saúde: Manguinhos, Rio de Janeiro, v. 12, suplemento, p. 309-321, 2005.

Artigo apresentado em 8/2008. Aprovado em $11 / 2008$. 